\title{
Transient Thermoelastic Analysis of Pressurized Rotating Disks Subjected to Arbitrary Boundary and Initial Conditions
}

\author{
Mohammad Zamani Nejad and Azam Afshin \\ Mechanical Engineering Department, Yasouj University, P.O. Box 75914-353, Yasouj, Iran \\ Correspondence should be addressed to Mohammad Zamani Nejad; m.zamani.n@gmail.com
}

Received 6 December 2013; Accepted 9 February 2014; Published 17 April 2014

Academic Editors: X. Li and B. Sun

Copyright ( 2014 M. Zamani Nejad and A. Afshin. This is an open access article distributed under the Creative Commons Attribution License, which permits unrestricted use, distribution, and reproduction in any medium, provided the original work is properly cited.

\begin{abstract}
This paper focuses on exact analytical solution of transient thermoelastic behaviors of rotating pressurized disks subjected to arbitrary boundary and initial conditions. The pressure, inner radius, and outer radius are considered constant. The basic thermoelasticity theory under generalized assumptions is used to solve the thermoelastic problem. Using the method of the separation of variables, the relations of temperature and transient thermal stresses in the radial direction are obtained. In the case study, the disk is considered under heat flux. Some useful discussions and numerical examples are presented. The analytical results were compared with those of the finite element method and good agreement was found. The relations obtained in this paper can be applied to any arbitrary boundary and initial conditions.
\end{abstract}

\section{Introduction}

The rotating disks subjected to mechanical and transient thermal loads are widely used in many engineering fields such as aerospace, mechanical, naval, nuclear energy, chemical plant, electronics, and biomaterials. Therefore, much research has been conducted in this field.

Cheung et al. [1] investigated the problem of transient thermal stresses in a solid elastic homogeneous and isotropic sphere for uniform and nonuniform local surface heating. Sugano [2] analyzed the problem of transient thermal stresses in a homogeneous transversely isotropic finite cylinder due to an arbitrary internal heat generation. A transient response of one-dimensional axisymmetric quasistatic-coupled thermoelastic problems was studied by Yang et al. [3]. Transient thermal stresses in cylindrically orthotropic tubes were obtained by Kardomateas [4]. The transient thermal stresses in a homogeneous cylindrically orthotropic hollow cylinder due to a constant temperature were imposed on one surface and heat convection into a medium at the other surface was studied by Kardomateas [5]. Ashida et al. [6] presented a general solution technique for transient thermoelasticity of transversely isotropic solids in cylindrical coordinates. For quasistatic problems, and without considering the effect of inertial term, Yee and Moon [7] obtained the closed-form solutions of the orthotropic hollow cylinder subjected to an arbitrary axisymmetric temperature distribution. Assuming that the material properties vary nonlinearly in the radial direction and that Poisson's ratio is constant, Zamani Nejad and Rahimi [8] obtained closed-form solutions for one-dimensional steady-state thermal stresses in a rotating functionally graded pressurized thick-walled hollow circular cylinder. In another study, they obtained a complete and consistent three-dimensional set of field equations by tensor analysis to characterize the behavior of FGM thick shells of revolution with arbitrary curvature and variable thickness along the meridional direction [9]. In this work, transient thermoelastic analysis of homogeneous and isotropic rotating disks under general boundary conditions was obtained.

\section{Temperature Analysis}

Consider a homogeneous isotropic hollow disk of inner and outer radii $r_{i}$ and $r_{o}$, respectively. One-dimensional transient 
heat conduction equation of disk, in the absence of heat source, for axisymmetric case is

$$
\begin{gathered}
\frac{1}{\alpha} \frac{\partial T}{\partial t}=\frac{\partial^{2} T}{\partial r^{2}}+\frac{1}{r} \frac{\partial T}{\partial r} \\
\alpha=\frac{k}{\rho c}
\end{gathered}
$$

where $T(r, t)$ is the temperature distribution, $\alpha$ is thermal diffusivity, and $k, \rho, c$ are the thermal conductivity, mass density, and specific heat capacity, respectively.

The initial and boundary conditions are as follows:

$$
\text { B.C: }\left\{\begin{array}{l}
C_{11} T\left(r_{i}, t\right)+\left.C_{12} \frac{\partial T}{\partial r}\right|_{r_{i}}=g_{1}, \\
C_{21} T\left(r_{o}, t\right)+\left.C_{22} \frac{\partial T}{\partial r}\right|_{r_{o}}=g_{2},
\end{array}\right.
$$

$$
\text { I.C }: T(r, 0)=T_{i}(r) \text {, }
$$

where $C_{i j}(i, j=1,2)$ and $g_{i}(i=1,2)$ are the constants dependent on the thermal boundary condition, and $T_{i}(r)$ is the given initial condition.

The solution of (1) may be obtained by the method of separation of variables, generalized Bessel function, and eigenfunction method as

$$
\begin{gathered}
T(r, t)=T_{h}(r, t)+T_{s}(r), \\
\frac{1}{r} \frac{\partial}{\partial r}\left(r \frac{\partial T_{s}}{\partial r}\right)=0, \\
\frac{1}{\alpha} \frac{\partial T_{h}}{\partial t}=\frac{\partial^{2} T_{h}}{\partial r^{2}}+\frac{1}{r} \frac{\partial T_{h}}{\partial r} .
\end{gathered}
$$

The boundary conditions are defined as follows:

$$
\begin{aligned}
& C_{11} T_{s}\left(r_{i}, t\right)+\left.C_{12} \frac{\partial T_{s}}{\partial r}\right|_{r_{i}}=g_{1}, \\
& C_{21} T_{s}\left(r_{o}, t\right)+\left.C_{22} \frac{\partial T_{s}}{\partial r}\right|_{r_{o}}=g_{2} .
\end{aligned}
$$

Integrating (4) twice yields

$$
T_{s}=C_{1} \ln (r)+C_{2} .
$$

Using the boundary conditions (see (6)) to determine the constants $C_{1}$ and $C_{2}$ yields

$$
C_{1}=\frac{C_{11} g_{2}-C_{21} g_{1}}{C_{21} C_{11} \ln \left(r_{o} / r_{i}\right)-\left(C_{21} C_{12} / r_{i}\right)+\left(C_{22} / r_{o}\right)},
$$

$C_{2}$

$$
=\frac{1}{C_{11}}\left(g_{1}-\frac{\left(C_{11} g_{2}-C_{21} g_{1}\right)\left(C_{11} \ln r_{i}+\left(C_{12} / r_{i}\right)\right)}{C_{21} C_{11} \ln \left(r_{o} / r_{i}\right)-\left(C_{21} C_{12} / r_{i}\right)+\left(C_{22} / r_{o}\right)}\right)
$$

or

$C_{2}$

$$
=\frac{1}{C_{21}}\left(g_{2}-\frac{\left(C_{11} g_{2}-C_{21} g_{1}\right)\left(C_{21} \ln r_{o}+\left(C_{22} / r_{o}\right)\right)}{C_{21} C_{11} \ln \left(r_{o} / r_{i}\right)-\left(C_{21} C_{12} / r_{i}\right)+\left(C_{22} / r_{o}\right)}\right) .
$$

For $T_{h}(r, t)$, boundary and initial conditions are as follows:

$$
\begin{aligned}
& \text { B.C : }\left\{\begin{array}{l}
C_{11} T_{h}\left(r_{i}, t\right)+\left.C_{12} \frac{\partial T_{h}}{\partial r}\right|_{r_{i}}=0, \\
C_{21} T_{h}\left(r_{o}, t\right)+\left.C_{22} \frac{\partial T_{h}}{\partial r}\right|_{r_{o}}=0,
\end{array}\right. \\
& \text { I.C : } T_{h}(r, 0)=T_{i}(r)-T_{s}(r)=T_{i}^{*}(r) .
\end{aligned}
$$

Thus, the solution for $T_{h}(r, t)$ is expressed as

$$
\begin{aligned}
& T_{h}(r, t)=\sum_{n=1}^{\infty} \frac{1}{\left\|f\left(r, \beta_{n}\right)\right\|^{2}} \\
& \times\left(\int_{r_{i}}^{r_{o}} T_{i}(r) f\left(r, \beta_{n}\right) r d r\right. \\
&+\left[\left(\left.\frac{r_{o}}{\beta_{n}^{2}}\left(C_{1} \ln \left(r_{o}\right)+C_{2}\right) \frac{\partial f\left(r, \beta_{n}\right)}{\partial r}\right|_{r=r_{o}}\right)\right. \\
& \quad-\left(\left.\frac{r_{i}}{\beta_{n}^{2}}\left(C_{1} \ln \left(r_{i}\right)+C_{2}\right) \frac{\partial f\left(r, \beta_{n}\right)}{\partial r}\right|_{r=r_{i}}\right) \\
&\left.\left.\quad+\frac{C_{1}}{\lambda_{n}^{2}}\left(\left(f\left(r_{o}, \beta_{n}\right)-f\left(r_{i}, \beta_{n}\right)\right)\right)\right]\right) \\
& \times f\left(r, \beta_{n}\right) e^{-\alpha t \beta_{n}^{2}},
\end{aligned}
$$

where

$$
\frac{\partial f\left(r, \beta_{n}\right)}{\partial r}=-\beta_{n}\left(A J_{1}\left(\beta_{n} r\right)+B Y_{1}\left(\beta_{n} r\right)\right) .
$$

Here $\beta_{n}$ are eigenvalue and are positive roots of the following equation:

$$
\begin{aligned}
& \left(C_{11} Y_{0}\left(\beta_{n} r_{i}\right)-\beta_{n} C_{12} Y_{1}\left(\beta_{n} r_{i}\right)\right) \\
& \quad \times\left(C_{21} J_{0}\left(\beta_{n} r_{o}\right)-\beta_{n} C_{22} J_{1}\left(\beta_{n} r_{o}\right)\right) \\
& \quad-\left(C_{21} Y_{0}\left(\beta_{n} r_{o}\right)-\beta_{n} C_{22} Y_{1}\left(\beta_{n} r_{o}\right)\right) \\
& \quad \times\left(C_{11} J_{0}\left(\beta_{n} r_{i}\right)-\beta_{n} C_{12} J_{1}\left(\beta_{n} r_{i}\right)\right)=0 .
\end{aligned}
$$

Here $J_{0}$ and $Y_{0}$ are Bessel functions of the first and the second kinds.

Eigenfunction $f\left(r, \beta_{n}\right)$ is as follows:

$$
f\left(r, \beta_{n}\right)=A J_{0}\left(\beta_{n} r\right)+B Y_{0}\left(\beta_{n} r\right) .
$$


$A$ and $B$ parameters are constant and are defined as

$$
\begin{aligned}
& A=C_{11} Y_{0}\left(\beta_{n} r_{i}\right)-C_{12} \beta_{n} Y_{1}\left(\beta_{n} r_{i}\right), \\
& B=-C_{11} J_{0}\left(\beta_{n} r_{i}\right)+C_{12} \beta_{n} J_{1}\left(\beta_{n} r_{i}\right)
\end{aligned}
$$

or

$$
\begin{aligned}
& A=C_{21} Y_{0}\left(\beta_{n} r_{o}\right)-C_{22} \beta_{n} Y_{1}\left(\beta_{n} r_{o}\right), \\
& B=-C_{21} J_{0}\left(\beta_{n} r_{o}\right)+C_{22} \beta_{n} J_{1}\left(\beta_{n} r_{o}\right) .
\end{aligned}
$$

$\left\|f\left(r, \beta_{n}\right)\right\|^{2}$ is the norm of eigenfunction and are obtained as

$$
\begin{aligned}
\left\|f\left(r, \beta_{n}\right)\right\|^{2}= & \int_{r_{i}}^{r_{o}} r f\left(r, \beta_{n}\right)^{2} d r \\
= & \frac{r_{o}^{2}}{2}\left(\left(A J_{0}\left(\beta_{n} r_{o}\right)+B Y_{0}\left(\beta_{n} r_{o}\right)\right)^{2}\right. \\
& \left.+\left(A J_{1}\left(\beta_{n} r_{o}\right)+B Y_{1}\left(\beta_{n} r_{o}\right)\right)^{2}\right) \\
& -\frac{r_{i}^{2}}{2}\left(\left(A J_{0}\left(\beta_{n} r_{i}\right)+B Y_{0}\left(\beta_{n} r_{i}\right)\right)^{2}\right. \\
& \left.\quad+\left(A J_{1}\left(\beta_{n} r_{i}\right)+B Y_{1}\left(\beta_{n} r_{i}\right)\right)^{2}\right) .
\end{aligned}
$$

\section{Transient Thermoelastic Analysis}

Consider thick hollow disk in the previous section at a constant angular velocity $\omega$ about its central axis. In the cylindrical coordinate system $(r, \theta, z)$, for the axisymmetric problem, radial and circumferential strains $\left(\varepsilon_{r r}, \varepsilon_{\theta \theta}\right)$ are as follows:

$$
\begin{gathered}
\varepsilon_{\theta \theta}=\frac{u_{r}}{r}, \\
\varepsilon_{r r}=\frac{\partial u_{r}}{\partial r} .
\end{gathered}
$$

Here, radial displacement $u_{r}$ is the only nonzero component of the displacement and is only the function of radial coordinate $r$.

For homogenous and isotropic disk, the linear thermoelastic constitutive relations can be expressed as follows:

$$
\begin{gathered}
\sigma_{r r}=\frac{E}{\left(1-\nu^{2}\right)}\left(\varepsilon_{r r}+\nu \varepsilon_{\theta \theta}-(1+\nu) \alpha T\right), \\
\sigma_{\theta \theta}=\frac{E}{\left(1-v^{2}\right)}\left(\varepsilon_{\theta \theta}+\nu \varepsilon_{r r}-(1+\nu) \alpha T\right), \\
T=T(r, t)-T_{0},
\end{gathered}
$$

where $E$ is modulus of elasticity, $\alpha$ is the coefficient of linear thermal expansion, $\nu$ is Poisson's ratio and $\sigma_{r r}$ and $\sigma_{\theta \theta}$ are components of stresses in radial and hoop directions, respectively, and $T_{0}$ is the reference temperature. Although, in this paper the reference temperature is taken as zero, the analysis would be valid for any nonzero value.
The equilibrium equation of the rotating hollow disk, in the absence of body forces, is expressed as

$$
\frac{\partial \sigma_{r r}}{\partial r}+\frac{\sigma_{r r}-\sigma_{\theta \theta}}{r}=-\rho r \omega^{2}
$$

where $\omega$ is angular velocity.

Substituting (18) into (19)-(20) and utilizing (22) yield

$$
\frac{\partial}{\partial r}\left(\frac{1}{r} \frac{\partial\left(u_{r} r\right)}{\partial r}\right)=(1+v) \alpha \frac{\partial T}{\partial r}-\frac{\left(1-v^{2}\right)}{E} \rho r \omega^{2}
$$

Integrating (23) twice yields

$$
u_{r}=A r+\frac{B}{r}+\frac{\alpha}{r}(1+v) \int_{r_{i}}^{r} \operatorname{Tr} d r-\frac{\left(1-v^{2}\right)}{8 E} \rho r^{3} \omega^{2} .
$$

Substituting (24) into (19)-(20), the radial and circumferential stresses of the rotating thick hollow disk are obtained as

$$
\begin{aligned}
\sigma_{r r}= & C_{1}^{*}-\frac{C_{2}^{*}}{r^{2}}-\frac{\alpha E}{r^{2}} \int_{r_{i}}^{r} \operatorname{Tr} d r-\frac{3+\nu}{8} \rho r^{2} \omega^{2}, \\
\sigma_{\theta \theta}= & C_{1}^{*}+\frac{C_{2}^{*}}{r^{2}}+\alpha E\left(\frac{1}{r^{2}} \int_{r_{i}}^{r} \operatorname{Tr} d r-T\right) \\
& -\frac{1+3 v}{8} \rho r^{2} \omega^{2},
\end{aligned}
$$

where

$$
C_{1}^{*}=\frac{A E}{1-v}, \quad C_{2}^{*}=\frac{B E}{1+v} .
$$

The mechanical boundary conditions are expressed as

$$
\begin{gathered}
\sigma_{r r}\left(r=r_{i}\right)=-P_{i}, \\
\sigma_{r r}\left(r=r_{o}\right)=-P_{o} .
\end{gathered}
$$

Substituting boundary conditions into (25) gives

$$
\begin{array}{r}
C_{1}^{*}=\frac{1}{r_{o}^{2}-r_{i}^{2}}\left(P_{i} r_{i}^{2}-P_{o} r_{o}^{2}+\alpha E \int_{r_{i}}^{r_{o}} T r d r\right. \\
\left.+\frac{3+v}{8} \rho \omega^{2}\left(r_{o}^{4}-r_{i}^{4}\right)\right), \\
C_{2}^{*}=\frac{r_{i}^{2} r_{o}^{2}}{r_{o}^{2}-r_{i}^{2}}\left(P_{i}-P_{o}+\frac{\alpha E}{r_{o}^{2}} \int_{r_{i}}^{r_{o}} \operatorname{Tr} d r\right. \\
\left.+\frac{3+\nu}{8} \rho \omega^{2}\left(r_{o}^{2}-r_{i}^{2}\right)\right) .
\end{array}
$$


Therefore,

$$
\begin{aligned}
\sigma_{r r}= & -P_{i}-\frac{1-\left(r_{i} / r\right)^{2}}{1-\left(r_{i} / r_{o}\right)^{2}}\left(P_{o}-P_{i}\right) \\
& -\frac{3+v}{8} \rho \omega^{2}\left(r^{2}-r_{i}^{2}\right)\left(1-\left(\frac{r_{o}}{r}\right)^{2}\right) \\
& +\frac{\alpha E}{r^{2}}\left(\frac{r^{2}-r_{i}^{2}}{r_{o}^{2}-r_{i}^{2}} \int_{r_{i}}^{r_{o}} \operatorname{Tr} d r-\int_{r_{i}}^{r} \operatorname{Tr} d r\right), \\
\sigma_{\theta \theta}= & -P_{i}-\frac{1+\left(r_{i} / r\right)^{2}}{1-\left(r_{i} / r_{o}\right)^{2}}\left(P_{o}-P_{i}\right) \\
& -\frac{1+3 v}{8} \rho \omega^{2}\left(r^{2}-\frac{1+3 v}{3+v}\left(r_{i}^{2}+r_{o}^{2}+\frac{r_{o}^{2} r_{i}^{2}}{r^{2}}\right)\right) \\
& +\frac{\alpha E}{r^{2}}\left(\int_{r_{i}}^{r} \operatorname{Tr} d r+\frac{r^{2}+r_{i}^{2}}{r_{o}^{2}-r_{i}^{2}} \int_{r_{i}}^{r_{o}} \operatorname{Tr} d r-r^{2} T\right),
\end{aligned}
$$

where

$$
\begin{aligned}
& \int_{r_{i}}^{r} T(r, t) r d r \\
& =\frac{C_{1}}{2}\left(r^{2} \ln (r)\right. \\
& \left.\quad-r_{i}^{2} \ln \left(r_{i}\right)-\frac{r^{2}-r_{i}^{2}}{2}\right) \\
& +\frac{C_{2}}{2}\left(r^{2}-r_{i}^{2}\right) \\
& +\sum_{n=1}^{\infty} \frac{e^{-\alpha t \beta_{n}^{2}}}{\left\|f\left(r, \beta_{n}\right)\right\|^{2}} \\
& \quad \times\left(\int_{r_{i}}^{r_{o}} T_{i}(r) f\left(r, \beta_{n}\right) r d r\right. \\
& \quad+\left[\left(\left.\frac{r_{o}}{\beta_{n}^{2}}\left(C_{1} \ln \left(r_{o}\right)+C_{2}\right) \frac{\partial f\left(r, \beta_{n}\right)}{\partial r}\right|_{r=r_{o}}\right)\right. \\
& \quad-\left(\left.\frac{r_{i}}{\beta_{n}^{2}}\left(C_{1} \ln \left(r_{i}\right)+C_{2}\right) \frac{\partial f\left(r, \beta_{n}\right)}{\partial r}\right|_{r=r_{i}}\right) \\
& \left.\left.\quad+\frac{C_{1}}{\beta_{n}^{2}}\left(f\left(r_{o}, \beta_{n}\right)-f\left(r_{i}, \beta_{n}\right)\right)\right]\right) \\
& \times\left(\left.\frac{r_{i}}{\beta_{n}^{2}} \frac{\partial f\left(r, \beta_{n}\right)}{\partial r}\right|_{r=r_{i}}-\frac{r}{\beta_{n}^{2}} \frac{\partial f\left(r, \beta_{n}\right)}{\partial r}\right) .
\end{aligned}
$$

\section{Results and Discussion}

Consider a disk with $r_{i}=0.4 \mathrm{~m}$ and $r_{o}=0.6 \mathrm{~m}$. The modulus of elasticity and Poisson's ratio, respectively, have values of $E=200 \mathrm{GPa}$ and $v=0.3$. The applied internal pressure is $70 \mathrm{MPa}$. The mass density is $\rho=7854 \mathrm{Kg} / \mathrm{m}^{3}$. The thermal diffusivity, thermal conductivity, and specific heat capacity are $\alpha=1.17\left(10^{-5}\right) 1 /{ }^{\circ} \mathrm{C}, k=60.5 \mathrm{~W} / \mathrm{m} \cdot \mathrm{K}$, and $c=434 \mathrm{~J} / \mathrm{Kg} \cdot \mathrm{K}$, respectively. In the following, the analytical solution described in the preceding section may be checked at two examples.

Example 1. Assume that the inner surface of disk is under heat flux and the outer surface of disc is under convection. The initial condition is a linear function in terms of the radius. Thus, thermal boundary condition is expressed as follows:

$$
\begin{aligned}
& \text { B.C: }\left\{\begin{aligned}
\left.k \frac{\partial T}{\partial r}\right|_{r=r_{i}}= & q=500 \mathrm{~W} / \mathrm{m}^{2} \\
-\left.k \frac{\partial T}{\partial r}\right|_{r=r_{o}} & =h\left(T_{\infty}-T\left(r_{o}, t\right)\right) \\
& =25\left(26.85-T\left(r_{o}, t\right)\right)
\end{aligned}\right. \\
& \text { I.C : } T(r, 0)=T_{i}(r)=20 r \text {. }
\end{aligned}
$$

Temperature distribution for this thermal boundary condition is

$$
\begin{aligned}
T(r, t) & \\
= & T_{\infty}+\frac{q r_{i}}{k}\left(\ln \frac{r}{r_{o}}-\frac{k}{r_{o} h}\right) \\
& +\pi \sum_{n=1}^{\infty} \frac{q+k h T_{\infty} \beta_{n} G_{n}}{\lambda_{n} k\left(1-G_{n}^{2}\left(h^{2}+k^{2} \beta_{n}^{2}\right)\right)} f\left(r, \beta_{n}\right) e^{-\alpha t \beta_{n}^{2}} \\
& -\frac{\pi^{2}}{2} \sum_{n=1}^{\infty} \frac{\beta_{n}^{2} f\left(r, \beta_{n}\right) e^{-\alpha t \beta_{n}^{2}}}{1-G_{n}^{2}\left(h^{2}+k^{2} \beta_{n}^{2}\right)} \int_{r_{i}}^{r_{o}} T_{i}(\eta) f\left(\eta, \beta_{n}\right) \eta d \eta,
\end{aligned}
$$

where

$$
\begin{aligned}
G_{n} & =\frac{Y_{1}\left(\beta_{n} r_{i}\right)}{\left(h Y_{0}\left(\beta_{n} r_{o}\right)-k \beta_{n} Y_{1}\left(\beta_{n} r_{o}\right)\right)} \\
& =\frac{J_{1}\left(\beta_{n} r_{i}\right)}{\left(h J_{0}\left(\beta_{n} r_{o}\right)-k \beta_{n} J_{1}\left(\beta_{n} r_{o}\right)\right)} .
\end{aligned}
$$

Figure 1 indicates temperature distribution for the course of 20 seconds for $r=0.45 \mathrm{~m}$. Figure 2 illustrates temperature distribution in the radial direction at $t=3 \mathrm{sec}$.

Figure 3 shows the comparison of the temperature distribution for different radii. As can be seen, temperature increases as radius increases. Figure 4 compares the temperature distribution for different times at point $r=0.45 \mathrm{~m}$. When $t \rightarrow \infty$, the variation of temperature versus dimensionless radius becomes linear.

Figures 5, 6, and 7 show the distribution of radial displacement, radial stress, and hoop stress versus radial direction. Meanwhile, this result is compared with FEM.

Figures 8, 9, and 10 show the distribution of radial displacement, radial stress, and hoop stress versus time.

Figures 11, 12, 13, 14, 15, and 16 show comparison of the displacement and stresses distribution for different time and 


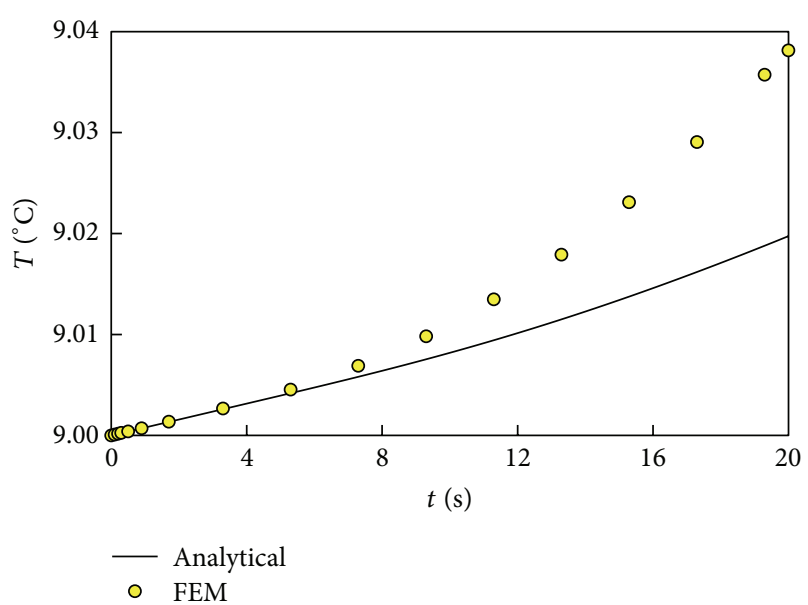

Figure 1: Temperature distribution $(r=0.45 \mathrm{~m})$.

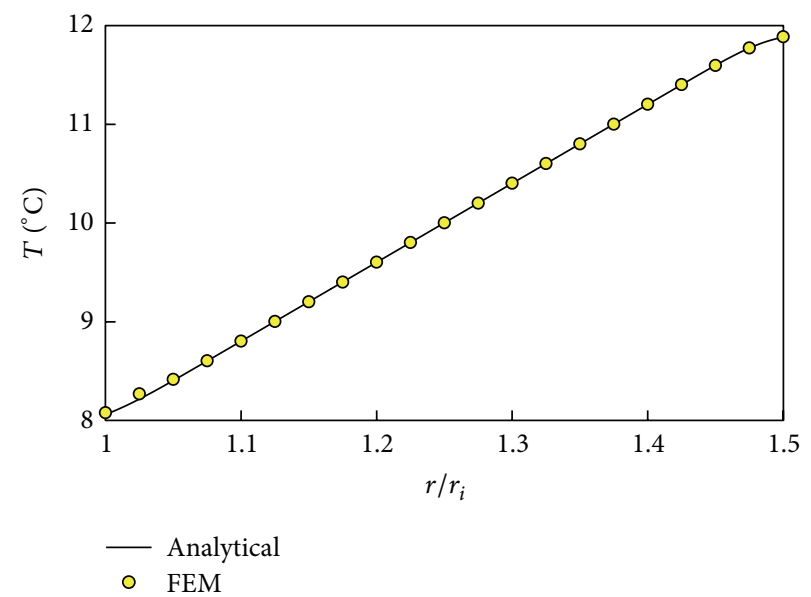

FIgURE 2: Temperature distribution in the radial direction $(t=$ $3 \mathrm{sec})$.

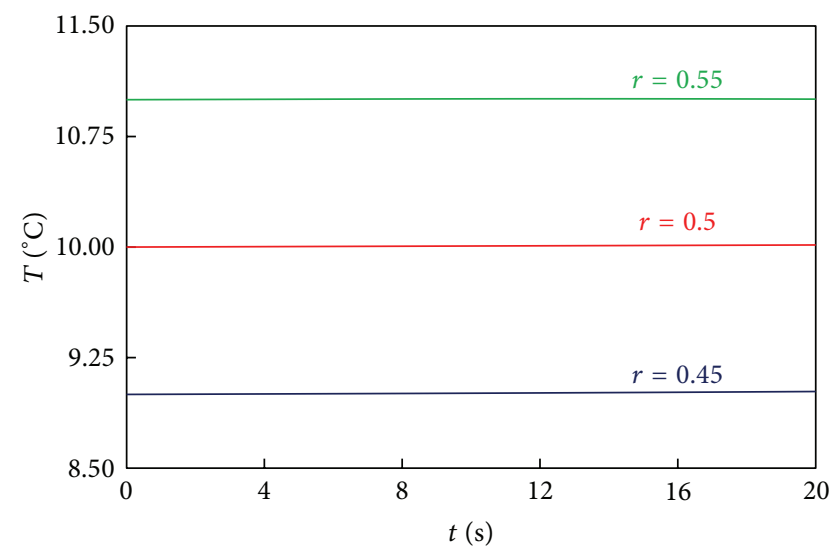

FIGURE 3: Comparison of the temperature distribution for different radius.

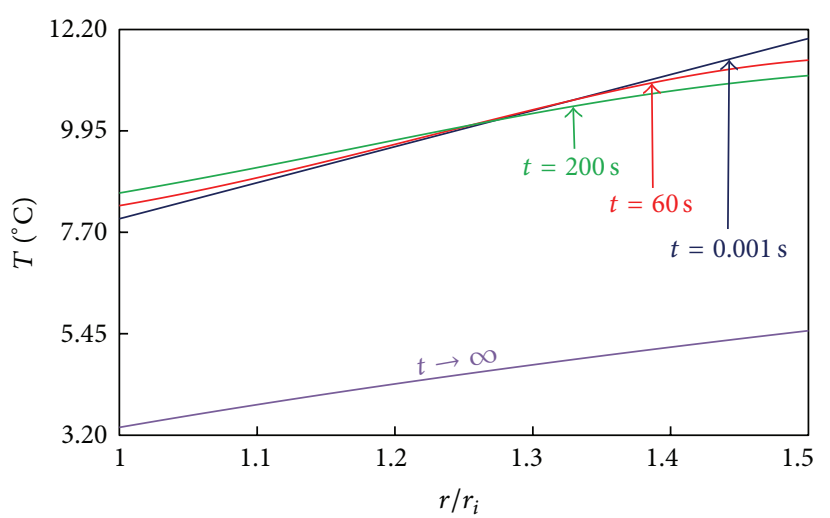

FIGURE 4: Comparison of the temperature distribution for different times.

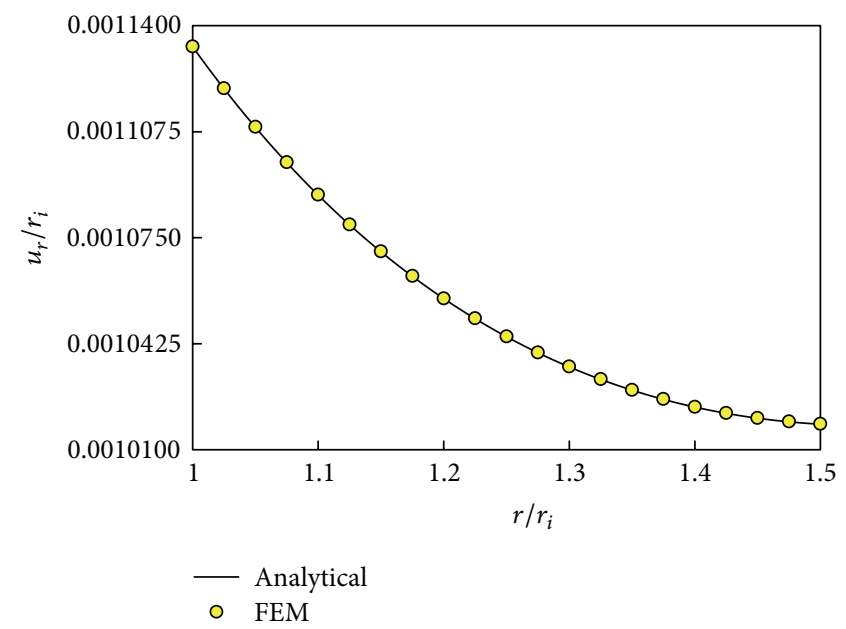

FIGURE 5: Radial displacement distribution $(t=3 \mathrm{sec})$.

different radius. Figures 14 and 16 show that variation of radial and hoop stresses into variation of time is very small. Figures $17,18,19,20,21$, and 22 show comparison of the displacement and stresses distribution for different angular velocity. (In these figures, $\omega$ is angular velocity and its dimension is radian per second $(\mathrm{rad} / \mathrm{sec})$.) In Figure 20 it is seen that angular velocity increases as radial stress decreases and if angular velocity increases more, radial stress changes from pressure to tension.

Example 2. Thermal boundary and initial conditions for the second example are

$$
\text { B.C : }\left\{\begin{array}{l}
T\left(r_{i}, t\right)=T_{1}=6^{\circ} \mathrm{C}, \\
-\left.k \frac{\partial T}{\partial r}\right|_{r=r_{o}}=q=-800 \mathrm{~W} / \mathrm{m}^{2},
\end{array}\right.
$$

I.C $: T(r, 0)=T_{i}(r)=20 r$. 


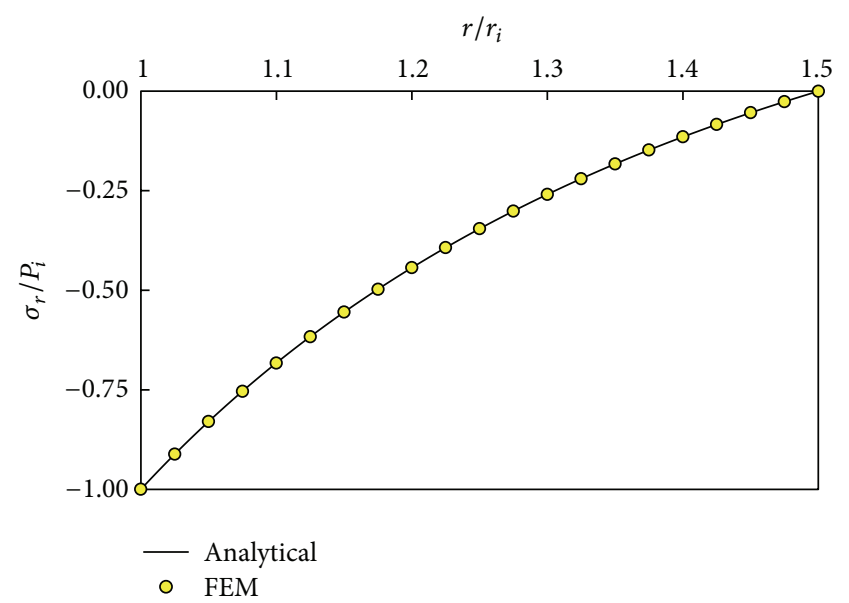

Figure 6: Radial stress distribution $(t=3 \mathrm{sec})$.

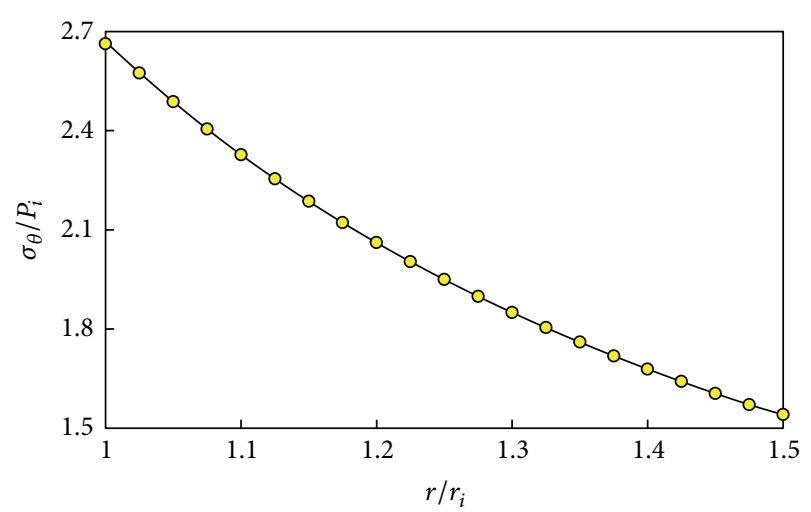

- Analytical

- FEM

FIgURE 7: Hoop stress distribution $(t=3 \mathrm{sec})$.

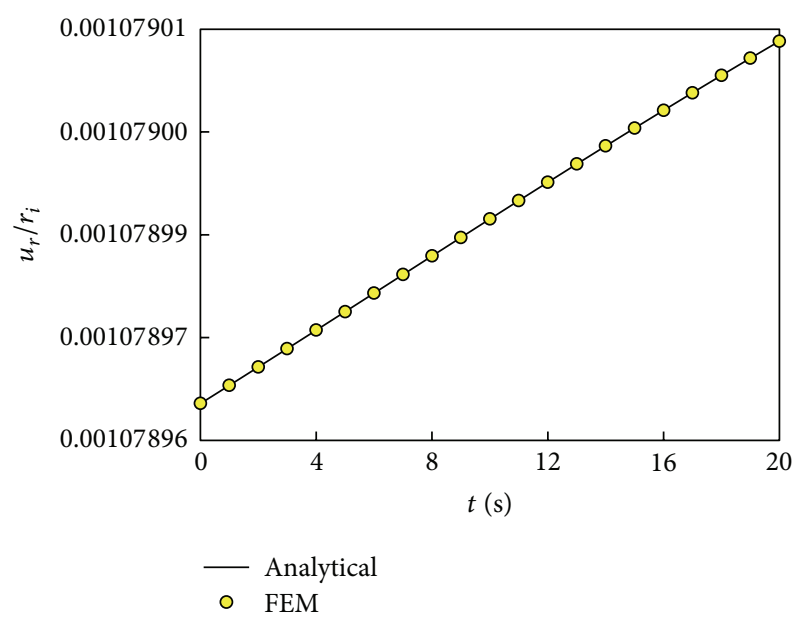

FIGURE 8: Radial displacement distribution $(r=0.45 \mathrm{~m})$.

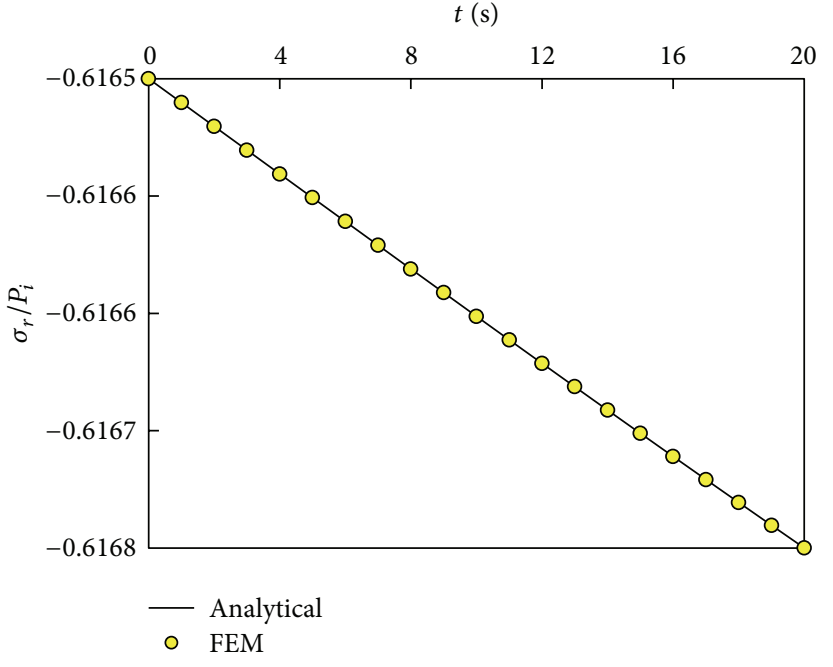

FIgURE 9: Radial stress distribution $(r=0.45 \mathrm{~m})$.

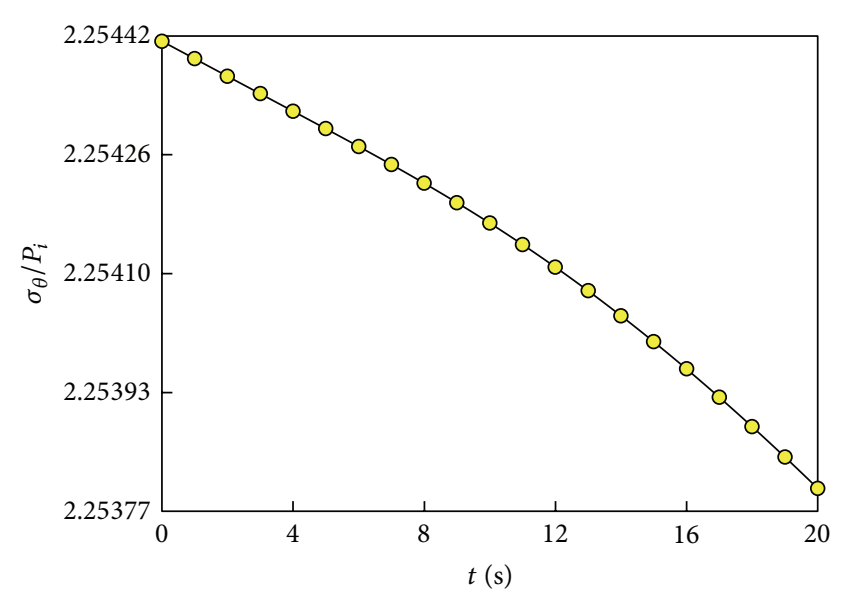

- Analytical

o FEM

FIGURE 10: Hoop stress distribution $(r=0.45 \mathrm{~m})$.

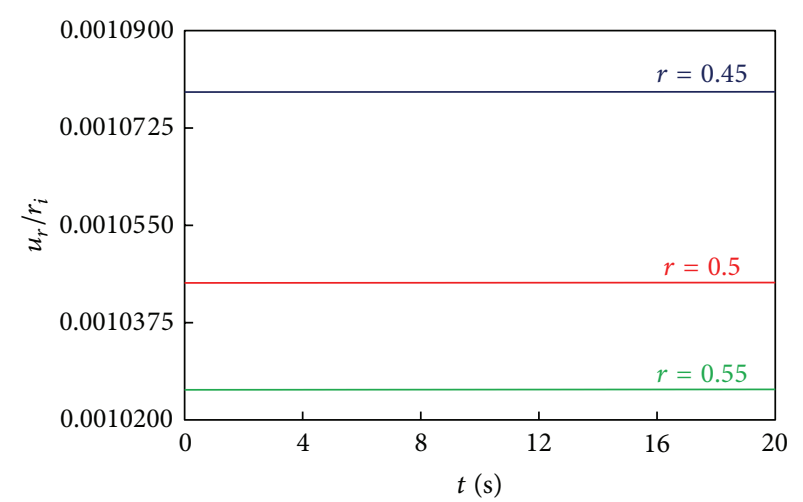

FIgURE 11: Comparison of the radial displacement distribution for different radius. 


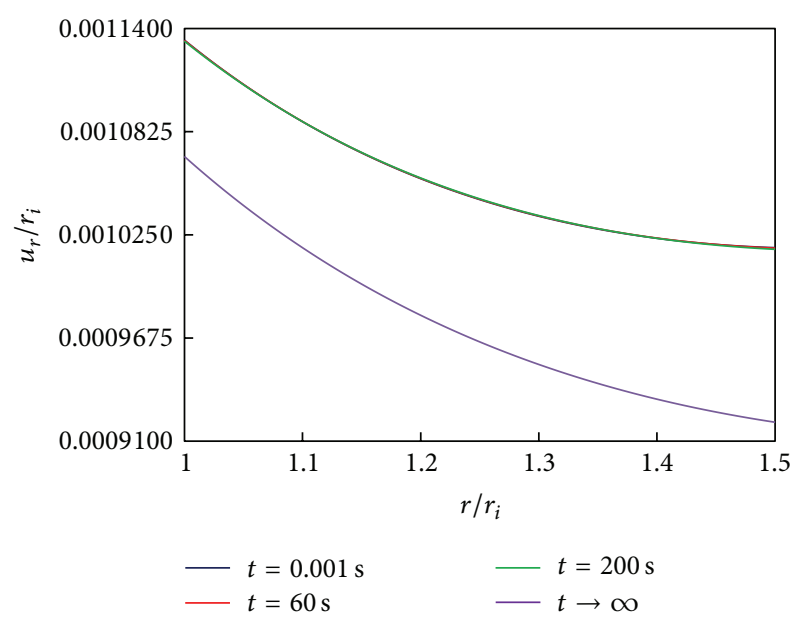

FIGURE 12: Comparison of the radial displacement distribution for different times.

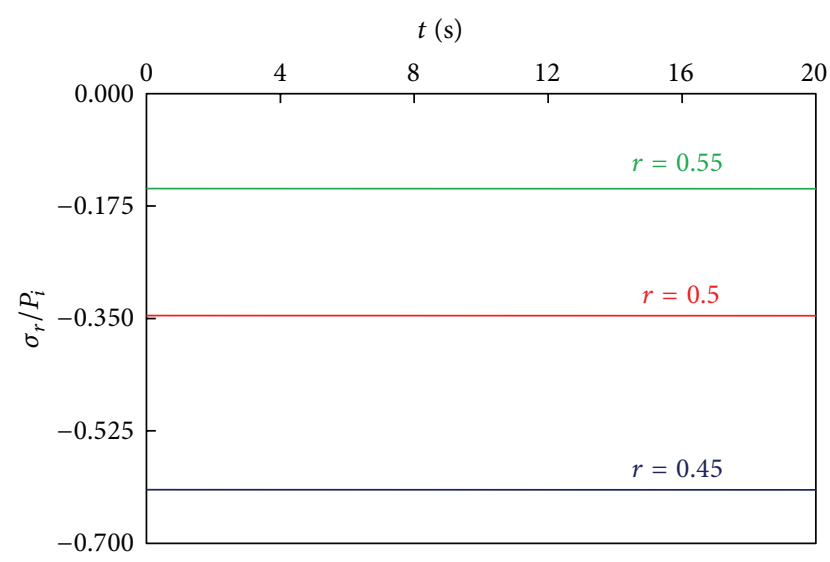

FIgURE 13: Comparison of the radial stress distribution for different radius.

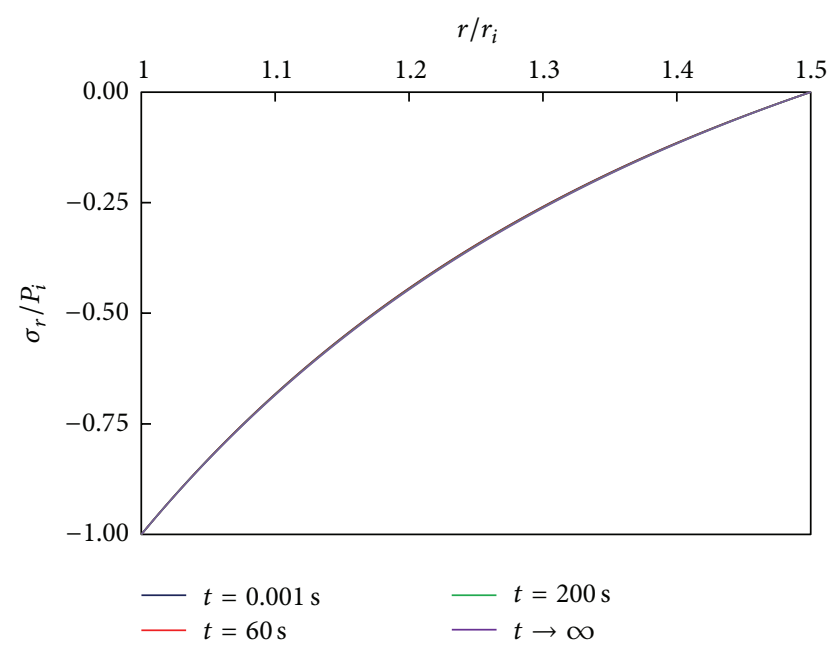

FIGURE 14: Comparison of the radial stress distribution for different times.

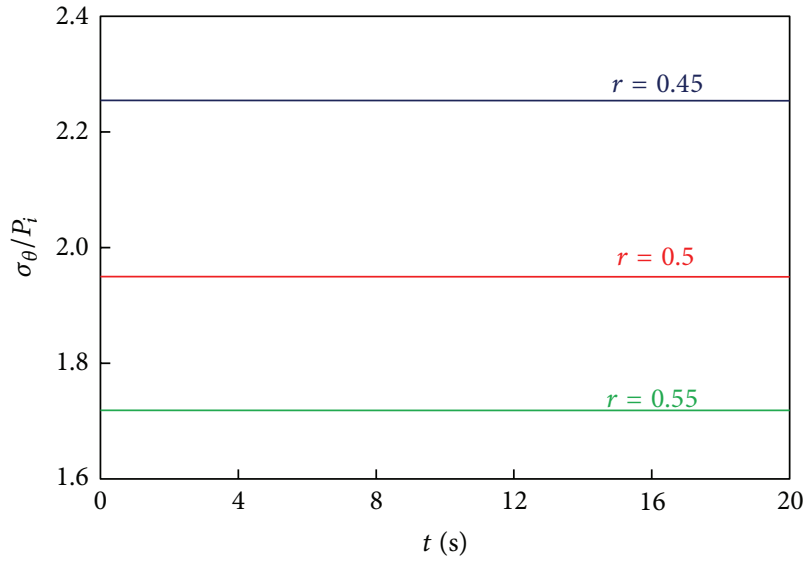

FIGURE 15: Comparison of the hoop stress distribution for different radius.

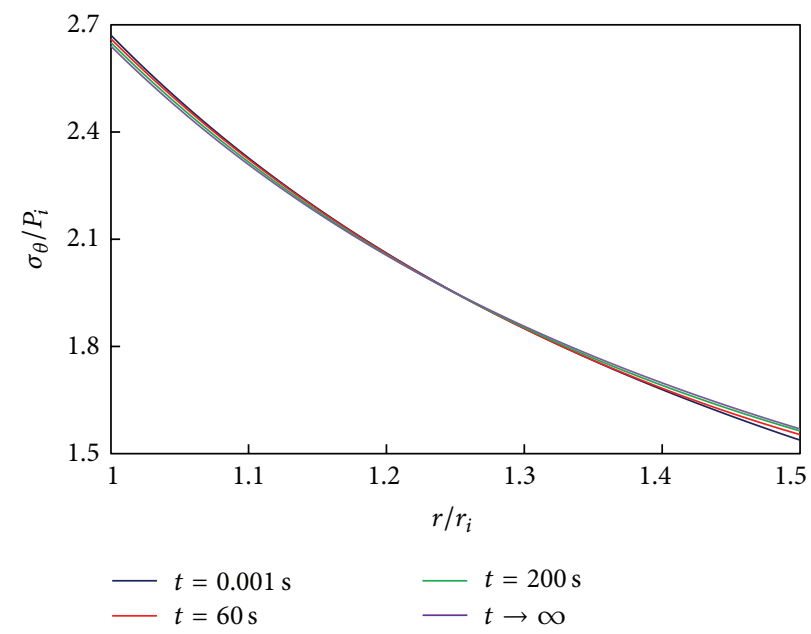

FIGURE 16: Comparison of the hoop stress distribution for different times.

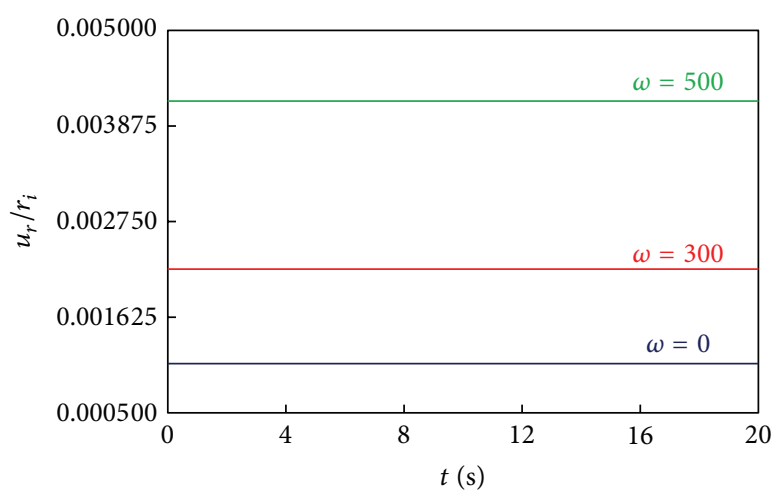

FIGURE 17: Comparison of the radial displacement distribution for different angular velocity $(r=0.45 \mathrm{~m})$. 


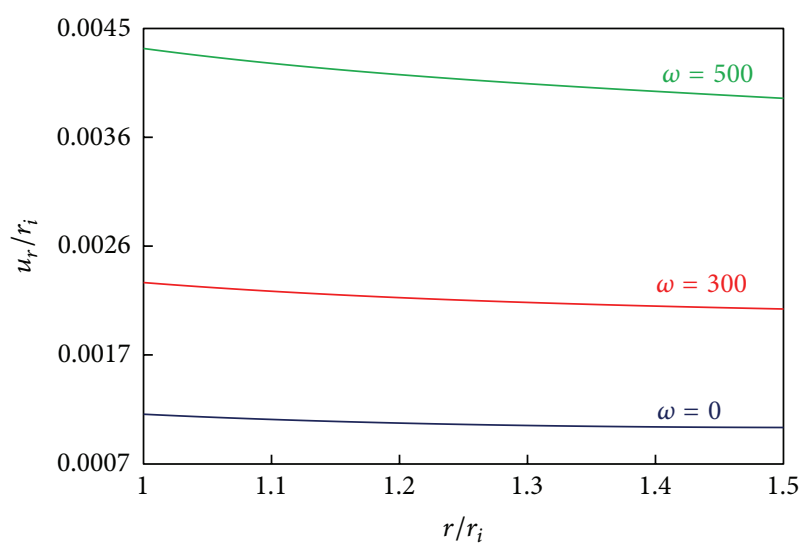

FIGURE 18: Comparison of the radial displacement distribution for different angular velocity $(t=3 \mathrm{sec})$.

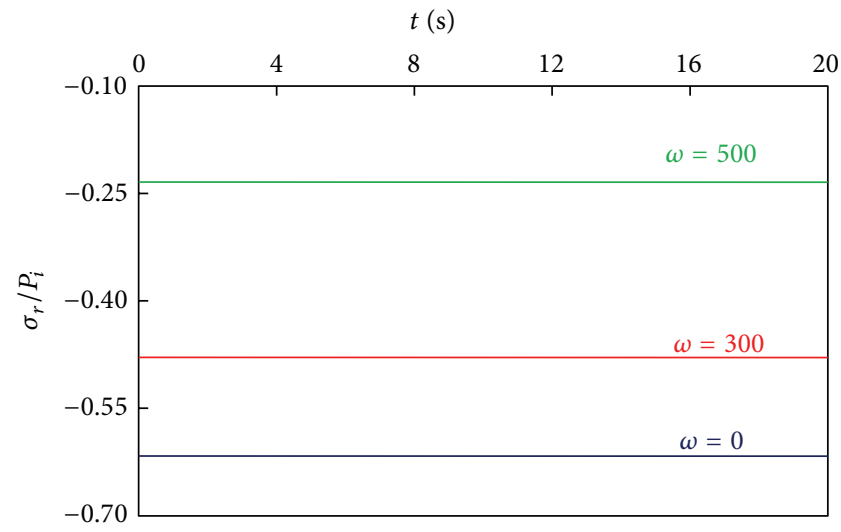

FIGURE 19: Comparison of the radial stress distribution for different angular velocity $(r=0.45 \mathrm{~m})$.

Temperature distribution for this thermal boundary condition is

$$
\begin{aligned}
T(r, t)= & T_{1}-\frac{q r_{o}}{k} \ln \frac{r}{r_{i}} \\
& -\pi \sum_{n=1}^{\infty} \frac{\left(k \beta_{n} T_{1} J_{1}\left(\beta_{n} r_{o}\right)-q J_{0}\left(\beta_{n} r_{i}\right)\right)}{k \beta_{n}\left(J_{1}^{2}\left(\beta_{n} r_{o}\right)-J_{0}^{2}\left(\beta_{n} r_{i}\right)\right)} \\
& \times J_{0}\left(\beta_{n} r_{i}\right) f\left(r, \beta_{n}\right) e^{-\alpha t \beta_{n}^{2}} \\
& -\frac{\pi^{2}}{2} \sum_{n=1}^{\infty} \frac{\beta_{n}^{2} J_{0}^{2}\left(\beta_{n} r_{i}\right)}{J_{1}^{2}\left(\beta_{n} r_{o}\right)-J_{0}^{2}\left(\beta_{n} r_{i}\right)} \\
& \times f\left(r, \beta_{n}\right) \int_{r_{i}}^{r_{o}} T_{i}(\eta) f\left(\eta, \beta_{n}\right) \eta d \eta e^{-\alpha t \beta_{n}^{2}} .
\end{aligned}
$$

Figure 23 indicates temperature distribution for the course of 20 seconds and Figure 24 illustrates temperature distribution in thickness; meanwhile the result of this state is compared with FEM.

Figure 25 shows comparison of the temperature distribution for different radius. As can be seen, temperature increases as radius increases. Figure 26 shows comparison

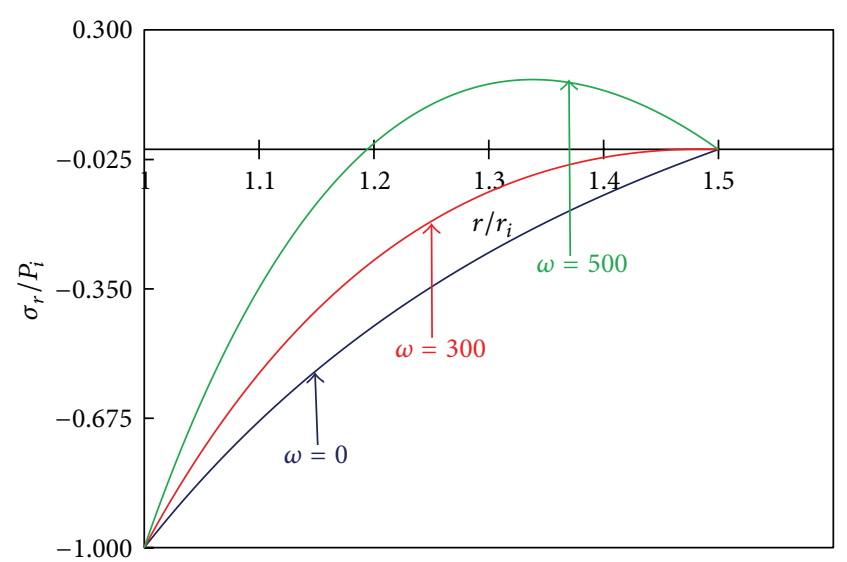

FIGURE 20: Comparison of the radial stress distribution for different angular velocity $(t=3 \mathrm{sec})$.

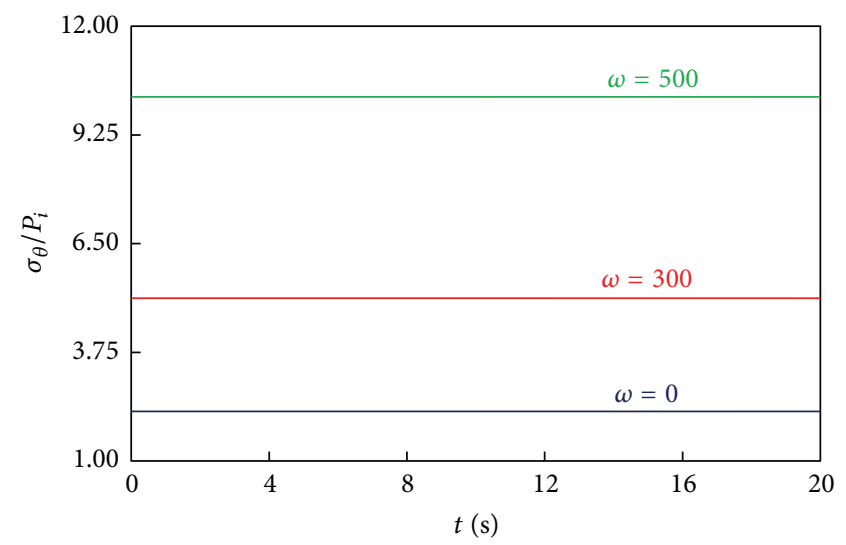

FIGURE 21: Comparison of the hoop stress distribution for different angular velocity $(r=0.45 \mathrm{~m})$.

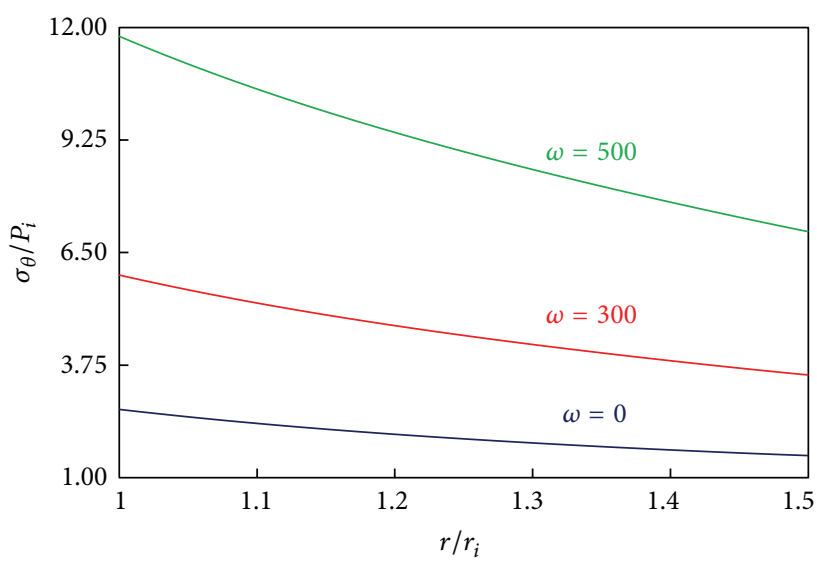

FIGURE 22: Comparison of the hoop stress distribution for different angular velocity $(t=3 \mathrm{sec})$.

of the temperature distribution for different times at point $r=0.45 \mathrm{~m}$. In the initial seconds and toward the inner radius the variation of temperature is intensive.

When $t \rightarrow \infty$ the variation of temperature versus dimensionless radius becomes linear. 


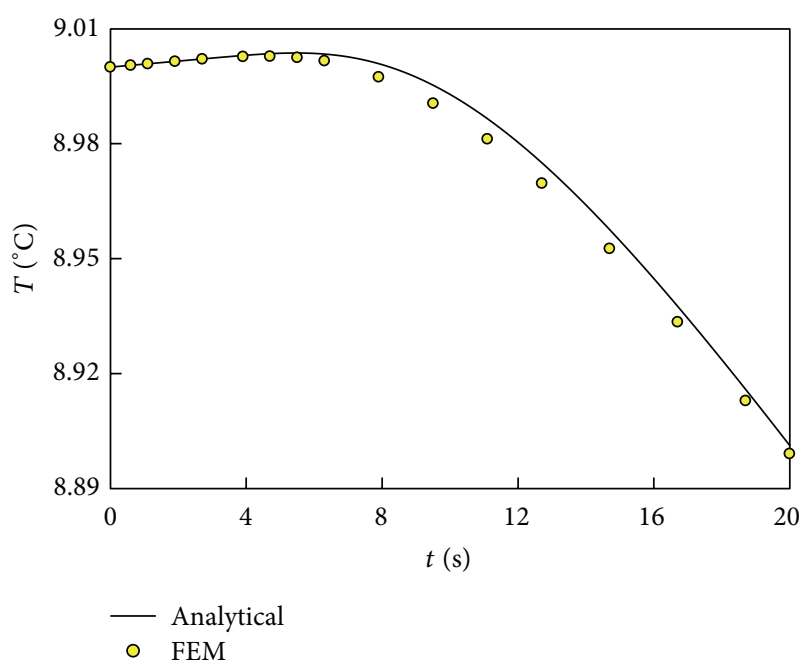

FIGURE 23: Temperature distribution $(r=0.45 \mathrm{~m})$.

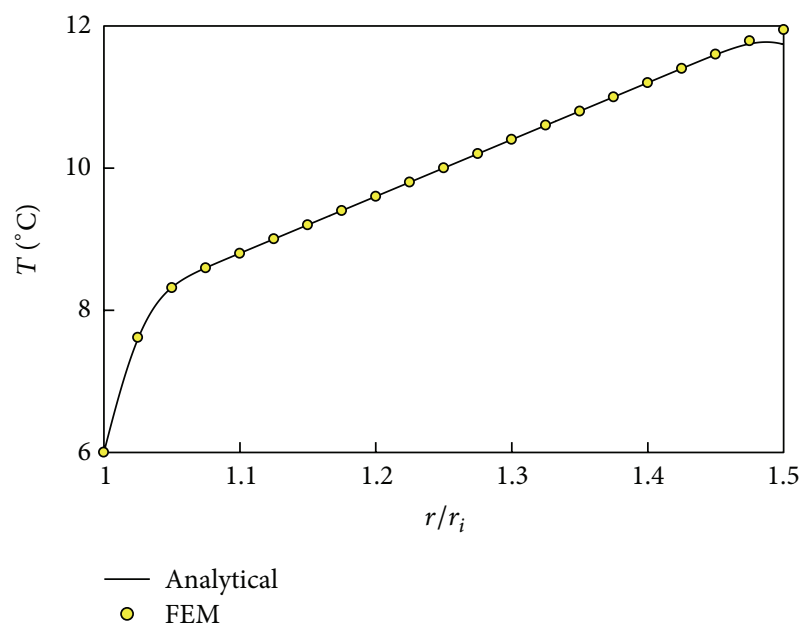

FIgURE 24: Temperature distribution in the radial direction $(t=$ $3 \mathrm{sec})$.

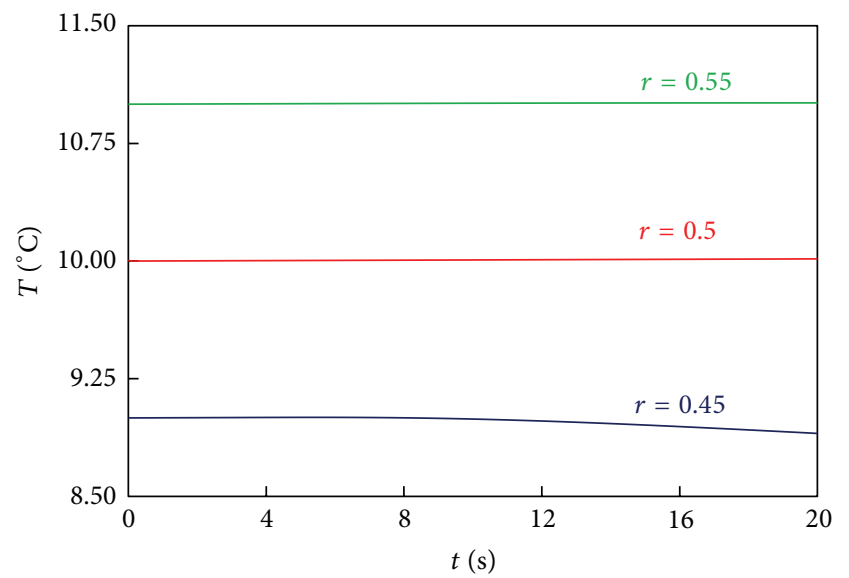

FIGURE 25: Comparison of the temperature distribution for different radius.

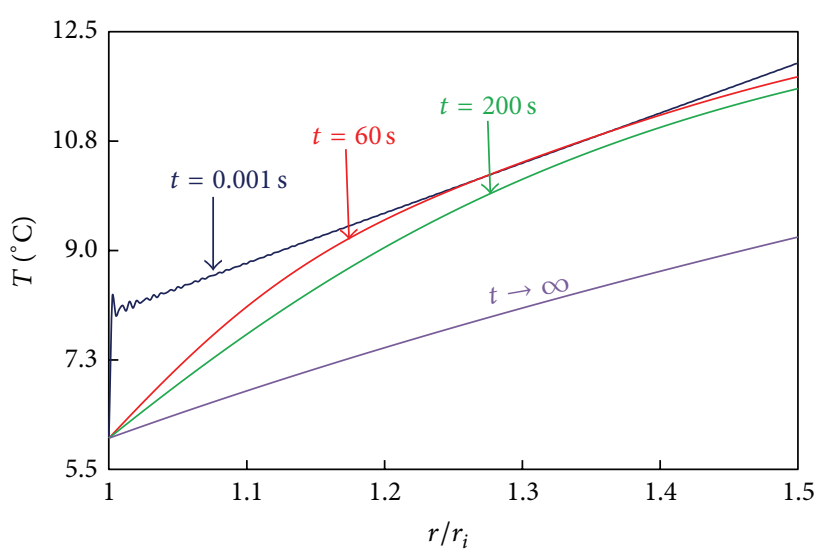

FIGURE 26: Comparison of the temperature distribution for different times.

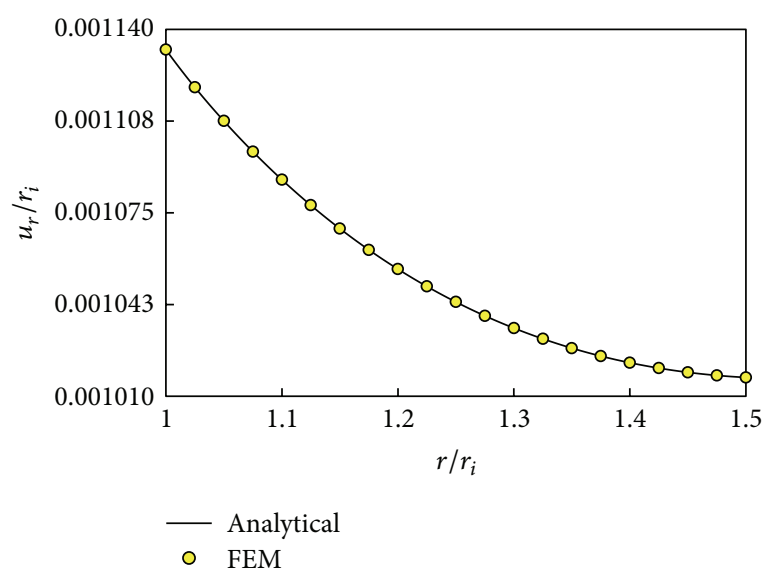

FIGURE 27: Radial displacement distribution $(t=3 \mathrm{sec})$.

Figures 27, 28, 29, 30, 31, and 32 show radial displacement and radial stress and hoop stress distribution versus time and thickness; meanwhile this result is compared with FEM. Figure 32 shows that in the course of 20 seconds hoop stress graphs have a minimum point. Figures 33, 34, 35, 36,37 , and 38 show comparison of the displacement and stresses distribution for different time and different radius. Figures 36 and 38 show that variation of radial and hoop stresses into variation of time is very small. Figures 39, 40, $41,42,43$, and 44 show comparison of the displacement and stresses distribution for different angular velocity. (In these figures, $\omega$ is angular velocity and its dimension is radian per second ( $\mathrm{rad} / \mathrm{sec})$.) In Figure 42 it is seen that angular velocity increases as radial stress decreases and if angular velocity increases more, radial stress changes from pressure to tension.

\section{Conclusions}

In the present study, an exact solution procedure has been presented for transient thermoelastic analysis of isotropic and homogeneous hollow disks under general initial and 


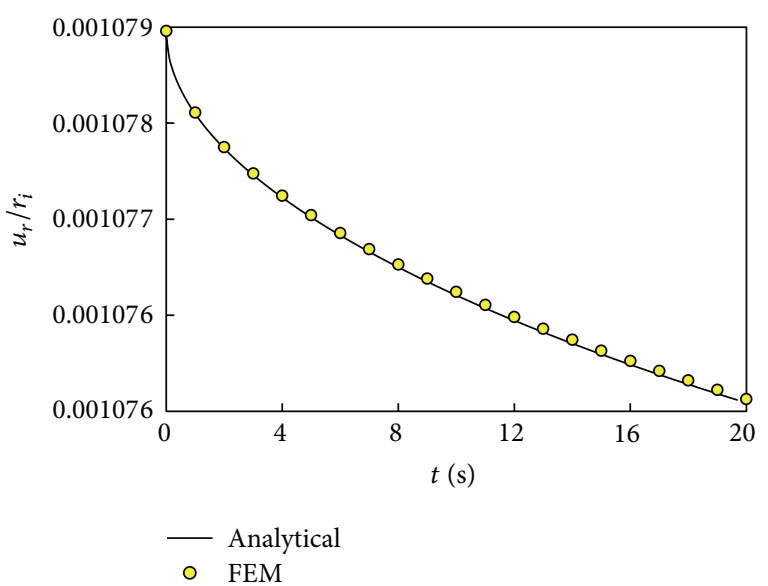

Figure 28: Radial displacement distribution $(r=0.45 \mathrm{~m})$.

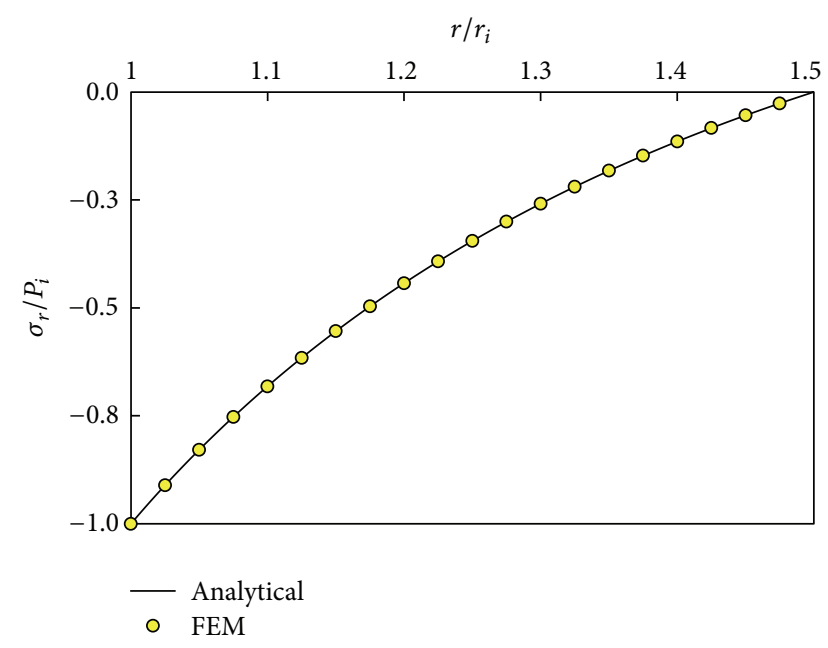

Figure 29: Radial stress distribution $(t=3 \mathrm{sec})$.

$t(\mathrm{~s})$

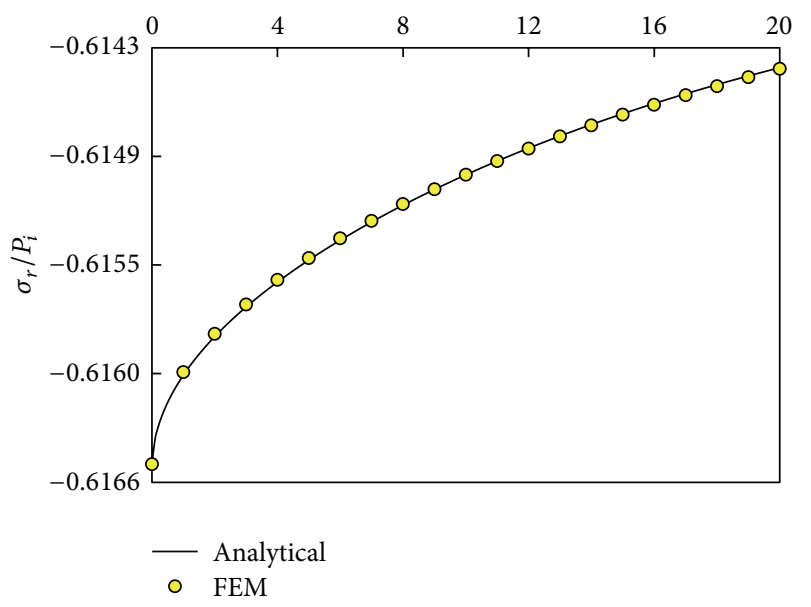

FIGURE 30: Radial stress distribution $(r=0.45 \mathrm{~m})$.

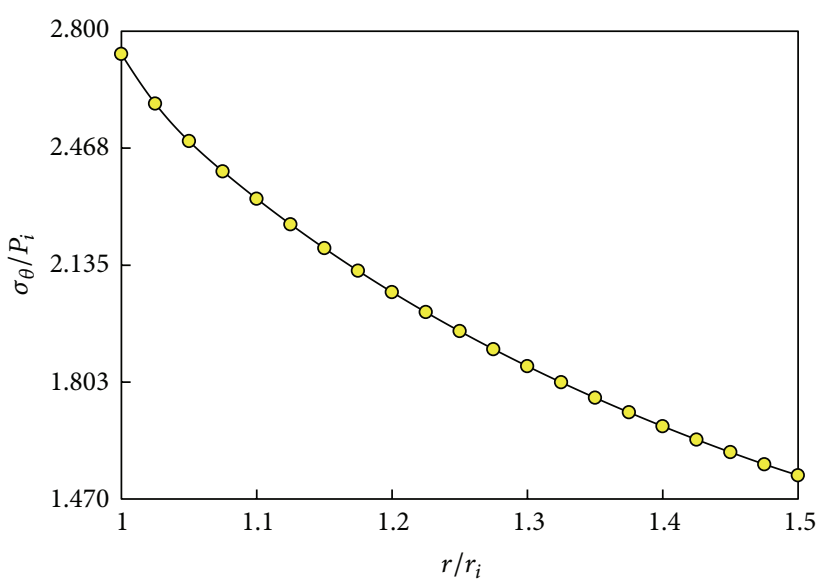

- Analytical

- FEM

FIGURE 31: Hoop stress distribution $(t=3 \mathrm{sec})$.

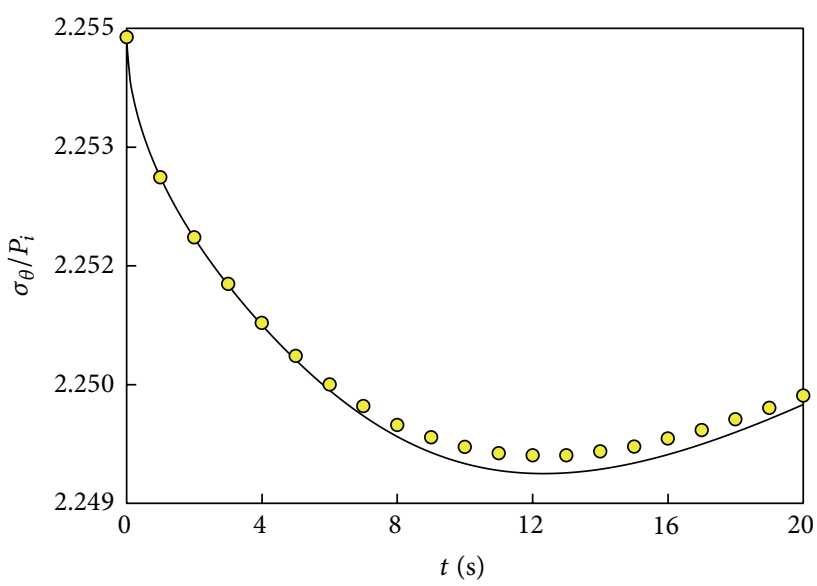

- Analytical
FEM

FIGURE 32: Hoop stress distribution $(r=0.45 \mathrm{~m})$.

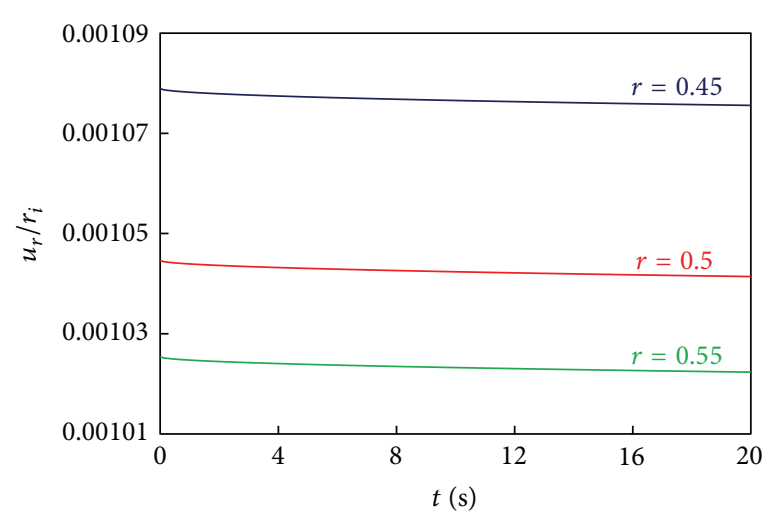

FIGURE 33: Comparison of the radial displacement distribution for different radius. 


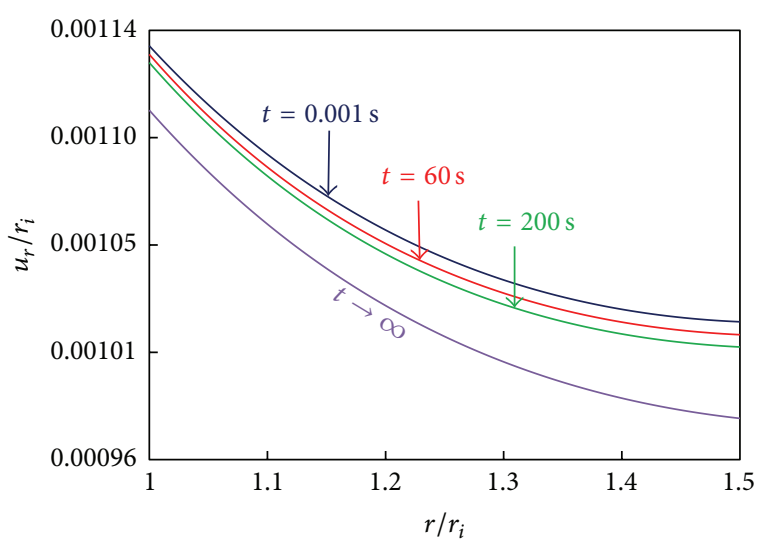

FIGURE 34: Comparison of the radial displacement distribution for different times.

$t(\mathrm{~s})$

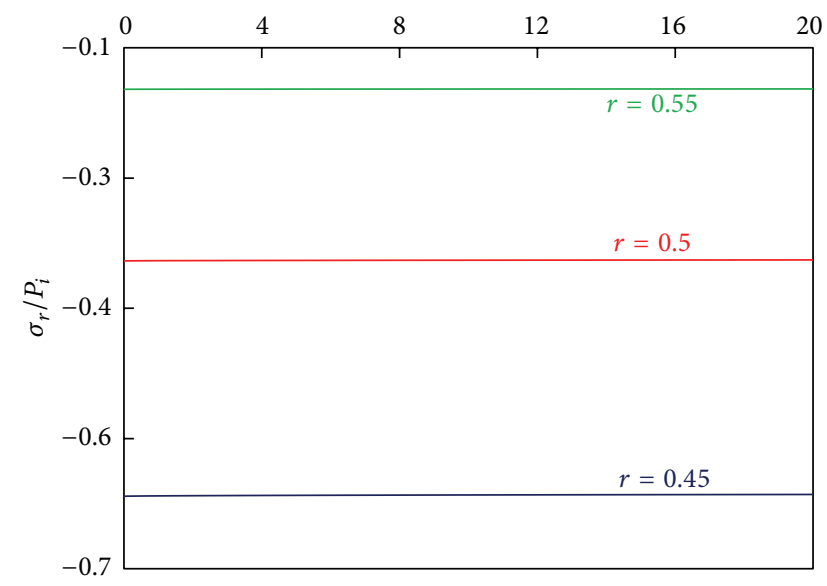

FIGURE 35: Comparison of the radial stress distribution for different radius.

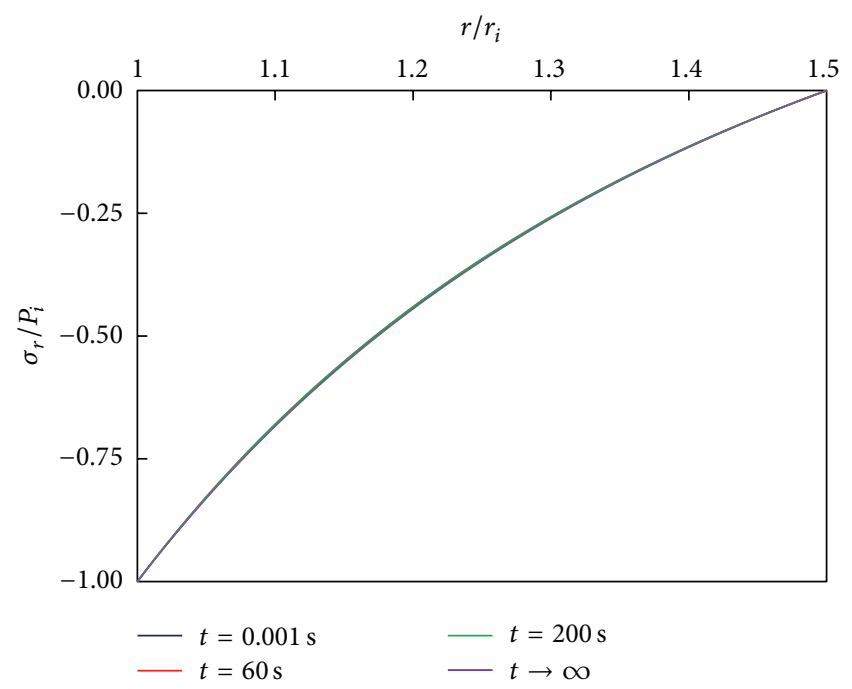

FIGURE 36: Comparison of the radial stress distribution for different times.

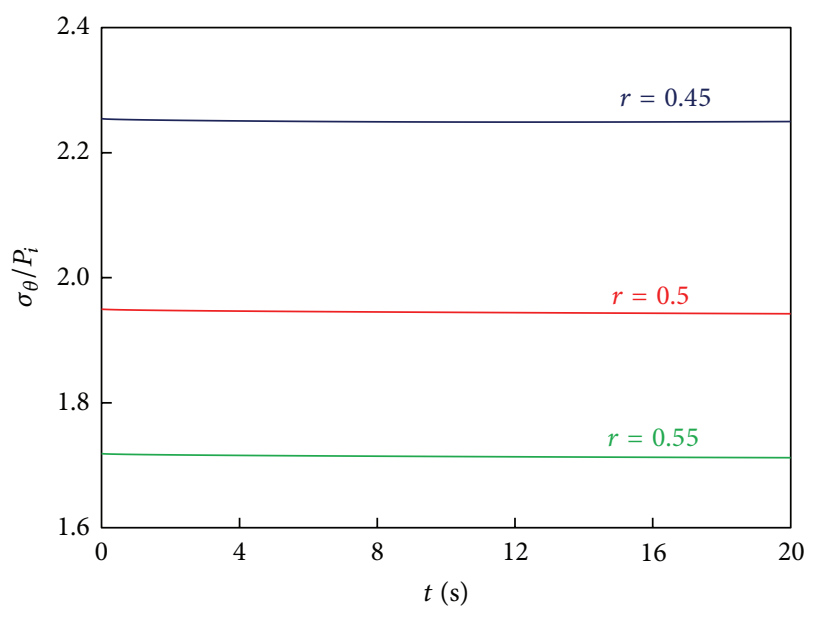

Figure 37: Comparison of the hoop stress distribution for different radius.

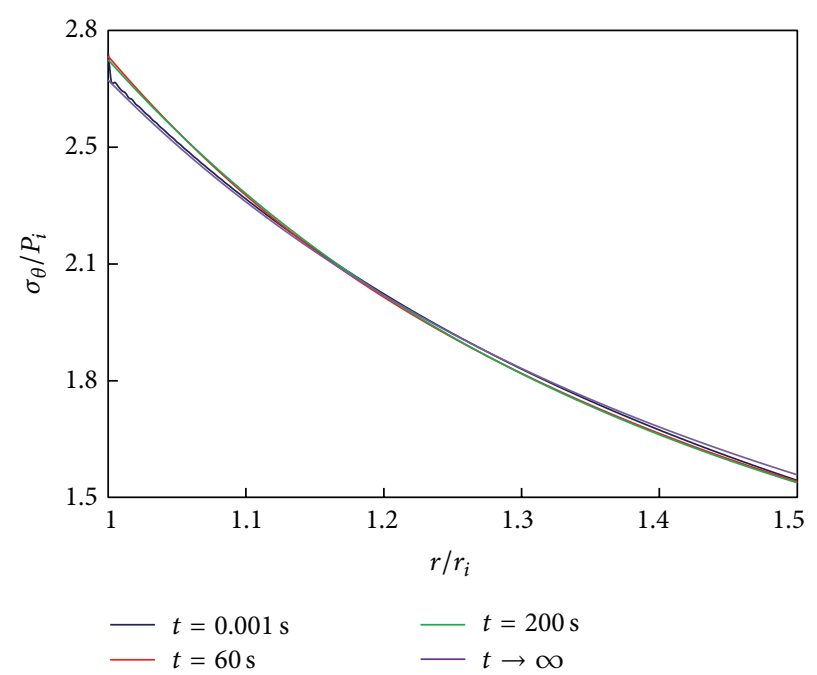

FIGURE 38: Comparison of the hoop stress distribution for different times.

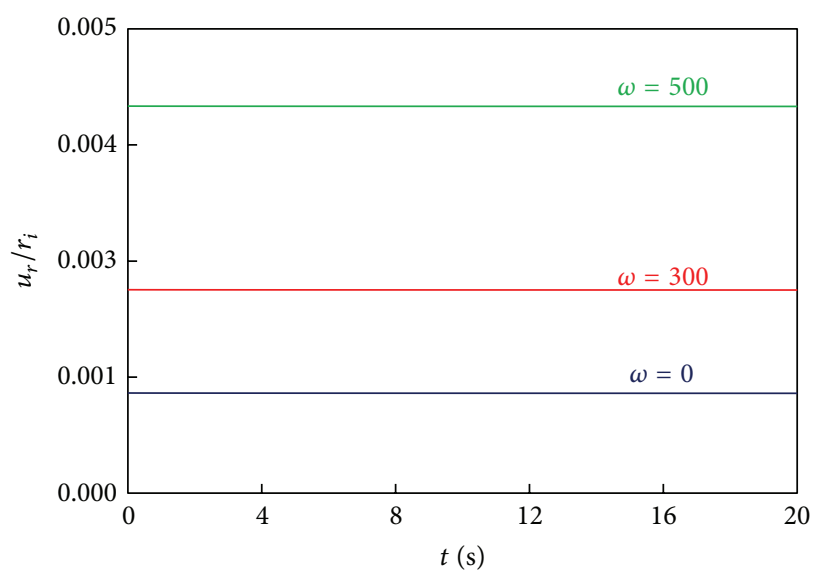

FIGURE 39: Comparison of the radial displacement distribution for different angular velocity $(r=0.45 \mathrm{~m})$. 


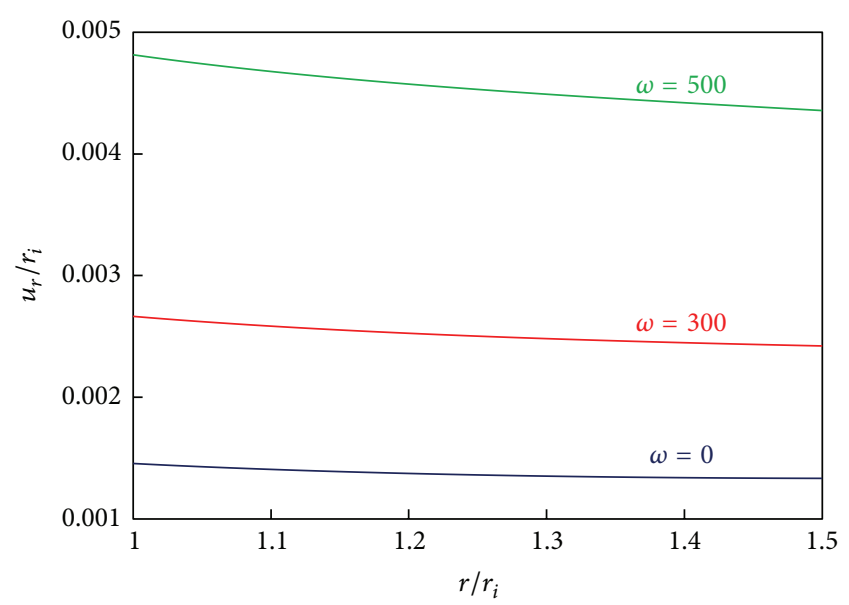

FIGURE 40: Comparison of the radial displacement distribution for different angular velocity $(t=3 \mathrm{sec})$.

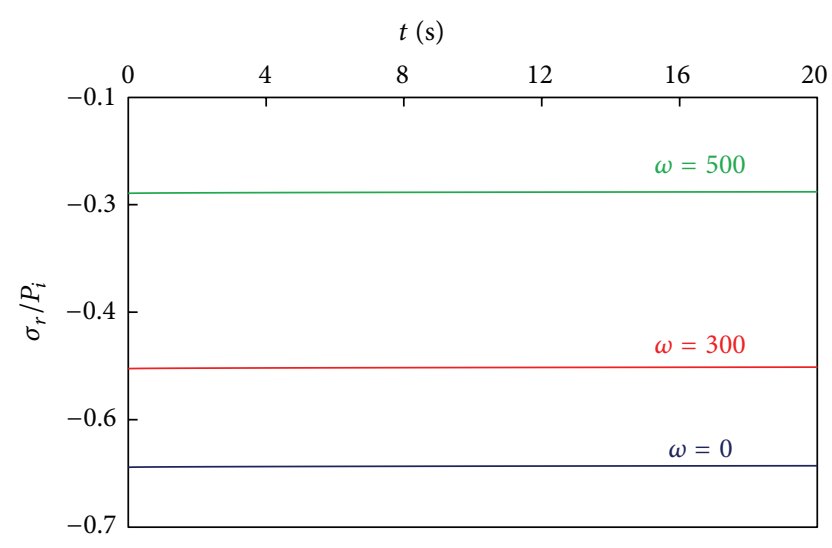

FIGURE 41: Comparison of the radial stress distribution for different angular velocity $(r=0.45 \mathrm{~m})$.

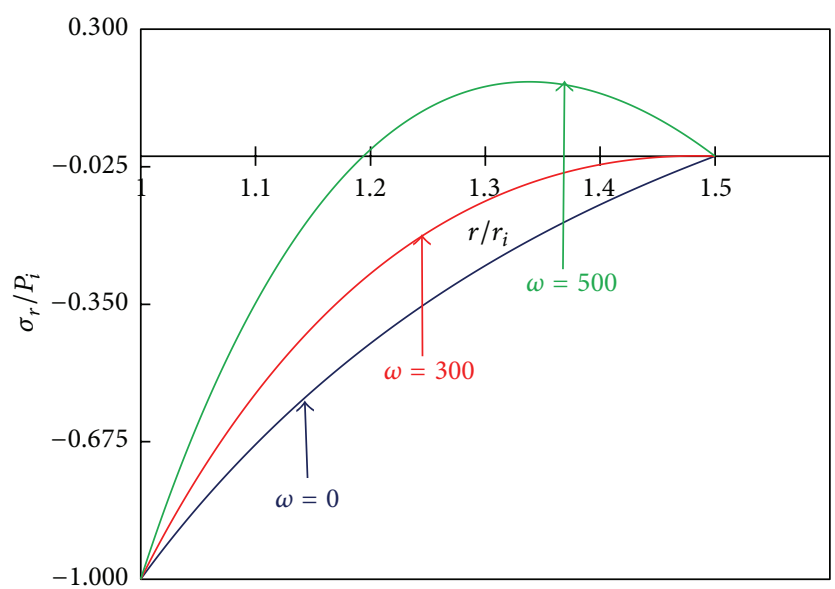

FIGURE 42: Comparison of the radial stress distribution for different angular velocity $(t=3 \mathrm{sec})$.

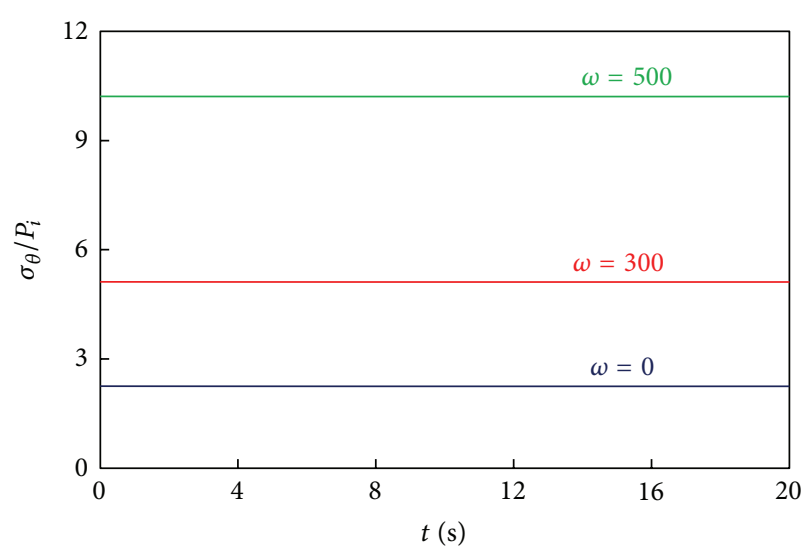

FIGURE 43: Comparison of the hoop stress distribution for different angular velocity $(r=0.45 \mathrm{~m})$.

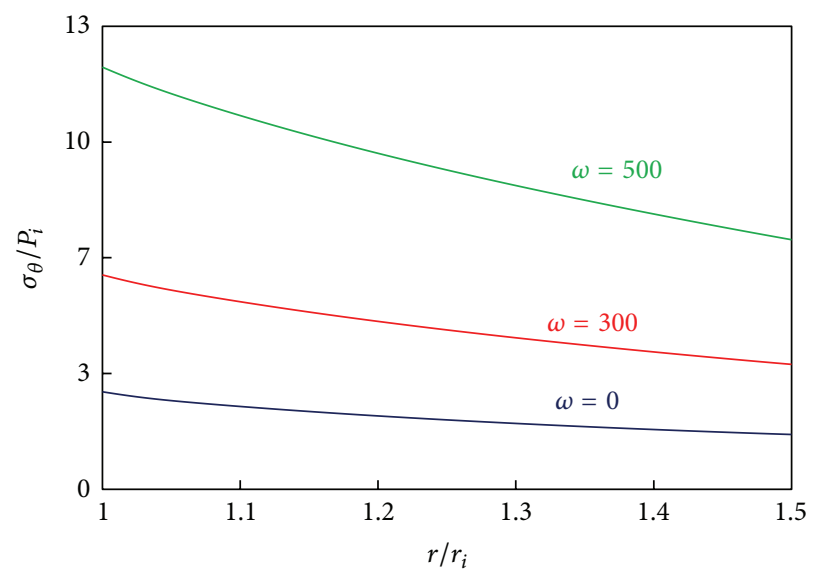

FIgURE 44: Comparison of the hoop stress distribution for different angular velocity $(t=3 \mathrm{sec})$.

boundary conditions. Some numerical results are shown in the figures. The distribution of the transient temperature, radial displacement, and thermal stresses through the radial direction of the disk is plotted and the results are compared with the solution using finite element method (FEM), which showed good agreement.

\section{Conflict of Interests}

The authors declare that there is no conflict of interests regarding the publication of this paper.

\section{References}

[1] J. B. Cheung, T. S. Chen, and K. Thirumalai, "Transient thermal stresses in a sphere by local heating," Journal of Applied Mechanics, vol. 41, no. 4, pp. 930-934, 1974.

[2] Y. Sugano, "Transient thermal stresses in a transversely isotropic finite circular cylinder due to an arbitrary internal heatgeneration," International Journal of Engineering Science, vol. 17, no. 8, pp. 927-939, 1979. 
[3] Y.-C. Yang, T.-S. Wang, and C.-K. Chen, "Thermoelastic transient response of an infinitely long annular cylinder," Journal of Thermal Stresses, vol. 9, no. 1, pp. 19-30, 1986.

[4] G. A. Kardomateas, "Transient thermal stresses in cylindrically orthotropic composite tubes," Journal of Applied Mechanics, vol. 56, no. 2, pp. 411-417, 1989.

[5] G. A. Kardomateas, "Initial phase of transient thermal stresses due to general boundary thermal loads in orthotropic hollow cylinders," Journal of Applied Mechanics, vol. 57, no. 3, pp. 719724, 1990.

[6] F. Ashida, N. Noda, and I. A. Okumura, "General solution technique for transient thermo elasticity of transversely isotropic solids in cylindrical coordinates," Acta Mechanica, vol. 101, no. 1-4, pp. 215-230, 1993.

[7] K.-C. Yee and T. J. Moon, "Plane thermal stress analysis of an orthotropic cylinder subjected to an arbitrary, transient, asymmetric temperature distribution," Journal of Applied Mechanics, vol. 69, no. 5, pp. 632-640, 2002.

[8] M. Zamani Nejad and G. H. Rahimi, "Deformations and stresses in rotating FGM pressurized thick hollow cylinder under thermal load," Scientific Research and Essays, vol. 4, no. 3, pp. 131-140, 2008.

[9] M. Zamani Nejad, G. H. Rahimi, and M. Ghannad, "Set of field equations for thick shell of revolution made of functionally graded materials in curvilinear coordinate system," Mechanika, vol. 77, no. 3, pp. 18-26, 2009. 

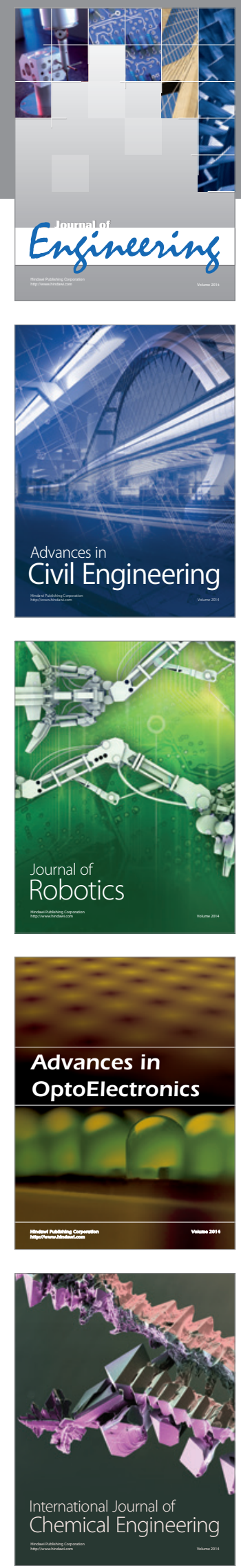

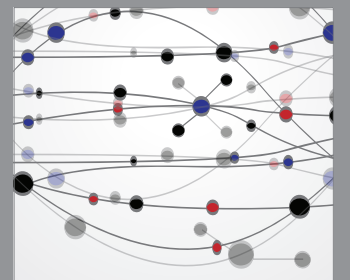

The Scientific World Journal
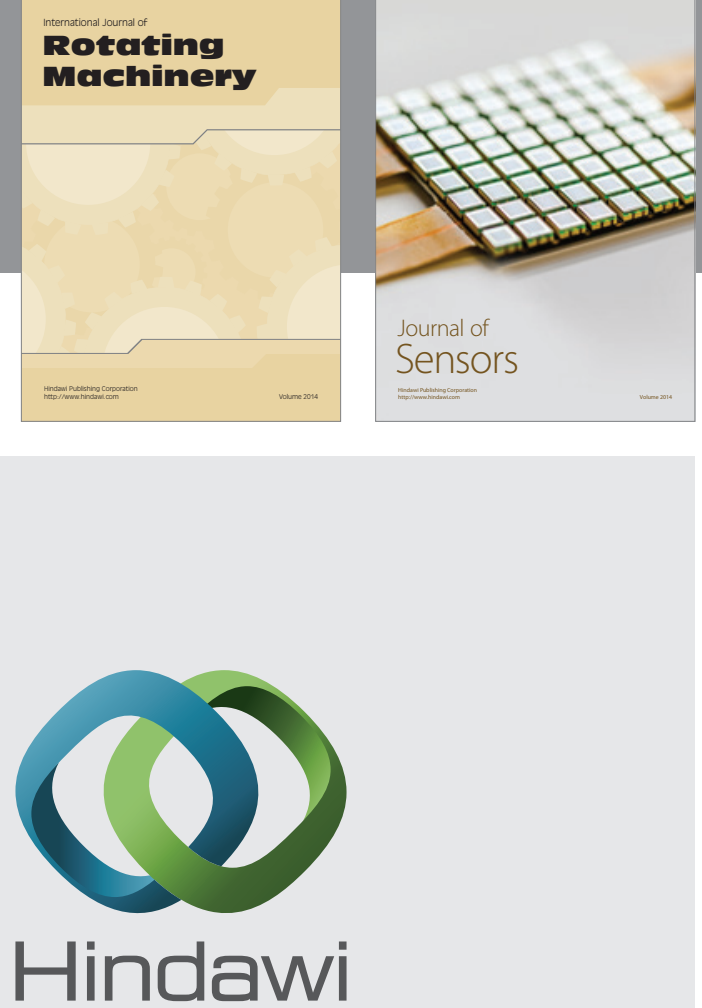

Submit your manuscripts at http://www.hindawi.com
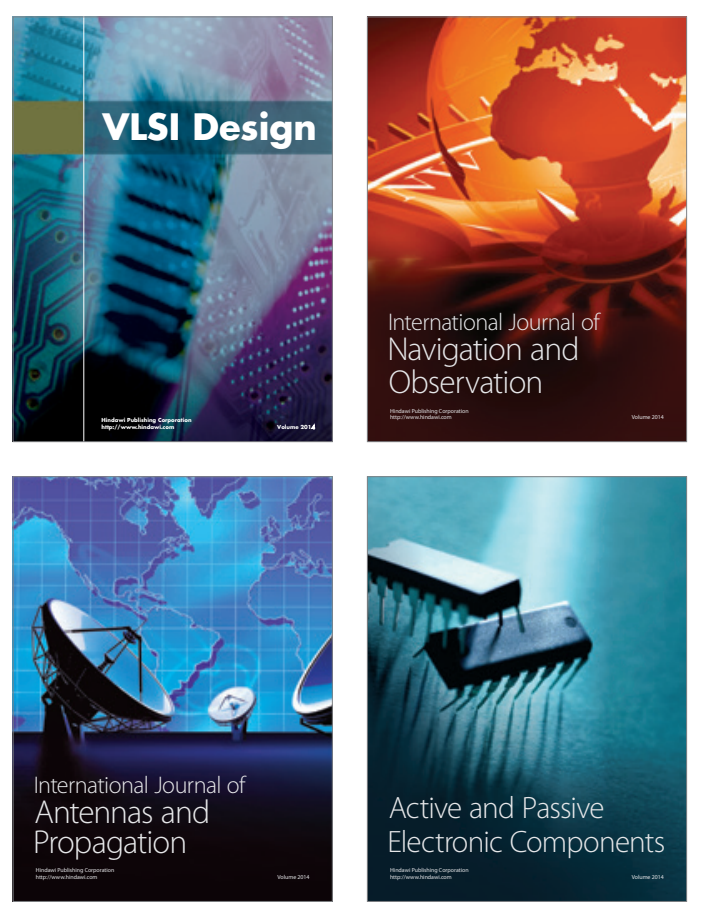
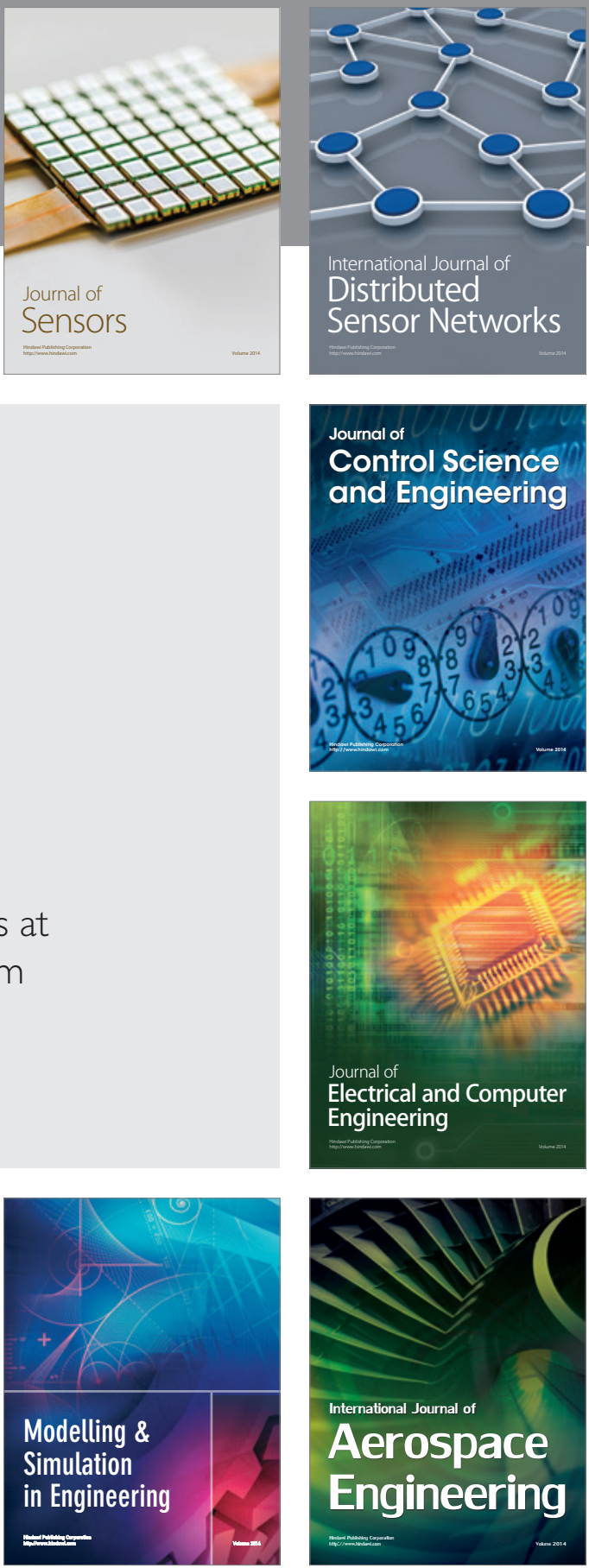

Journal of

Control Science

and Engineering
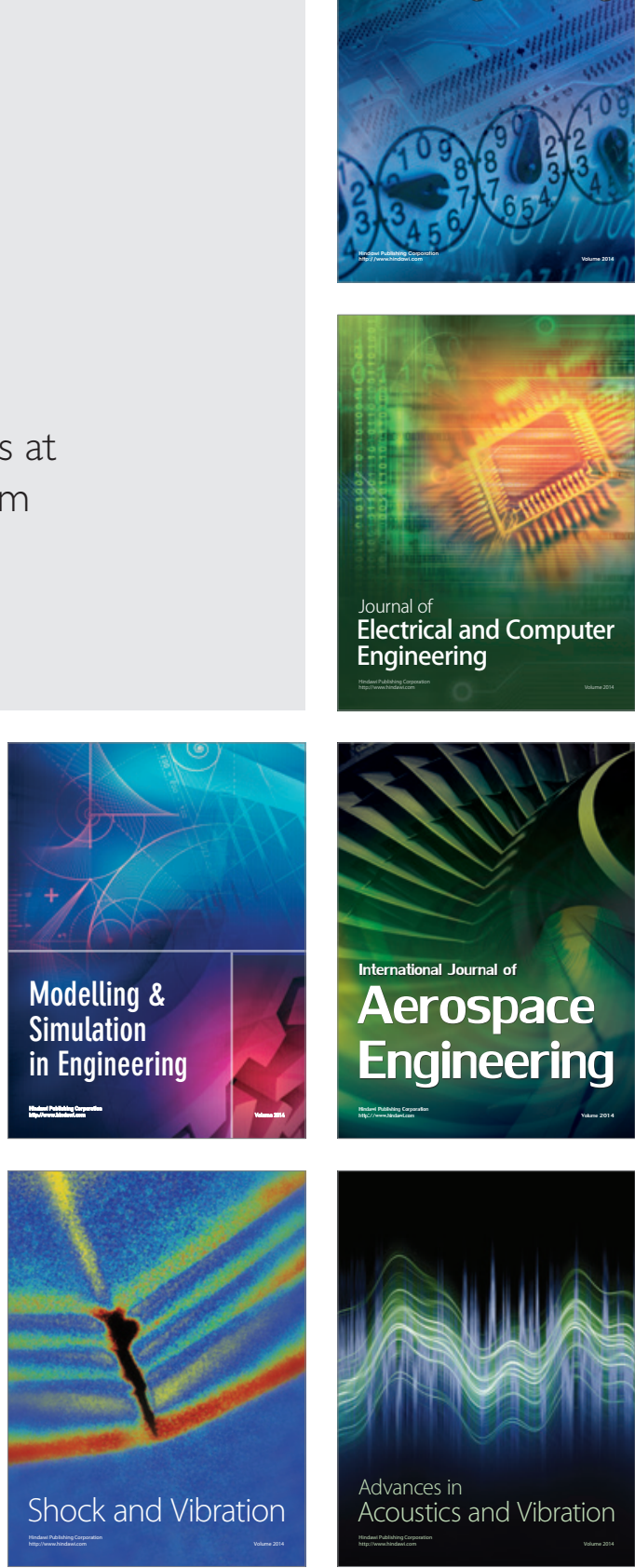